\title{
Underlying structural control of small-scale faults and fractures in West Candor Chasma, Mars
}

\author{
C. Birnie, ${ }^{1}$ F. Fueten, ${ }^{1}$ R. Stesky, ${ }^{2}$ and E. Hauber ${ }^{3}$ \\ Received 29 May 2012; revised 4 September 2012; accepted 18 September 2012; published 2 November 2012.
}

[1] Orientations of small-scale faults and fractures within the interior layered deposits of West Candor Chasma were measured to investigate what information about the geologic history of Valles Marineris they can contribute. Deformational features were separated into six categories based on morphology and their orientations were analyzed. The elevations at which the deformational features formed are recorded, as a proxy for stratigraphic level. Deformational features occur over a continuous range of elevations and display regionally consistent preferred orientations, indicating their formation was controlled by a regional stress regime. The two most abundant preferred orientations of $\sim 35^{\circ}$ and $\sim 110^{\circ}$ are approximately parallel to the chasma walls and the inferred underlying normal faults. The alignment of three populations of small faults at $140^{\circ}$, consistent with the morphology of release faults, indicates a large-scale fault underlying the southeastern border of Ceti Mensa. The preferred orientations imply these small-scale deformational features formed from a continuation of the same imposed stresses responsible for the formation of Valles Marineris, indicating these stresses existed past the formation of the interior layered deposits. The origins of a fourth preferred orientation of $70^{\circ}$ is less clear but suggests the study area has undergone at least two periods of deformation.

Citation: Birnie, C., F. Fueten, R. Stesky, and E. Hauber (2012), Underlying structural control of small-scale faults and fractures in West Candor Chasma, Mars, J. Geophys. Res., 117, E11001, doi:10.1029/2012JE004144.

\section{Introduction}

[2] Regional mapping of small-scale deformational features on Mars can reveal significant information about the regional stress history and the material being deformed. Structural analysis of Valles Marineris has previously been focused on large structural features, such as linear chasma walls and pit crater chains [e.g., Schultz, 1998; Schultz and Lin, 2001] that define the distinct west-northwest orientation of Valles Marineris, or the localized deformation of Interior Layered Deposits (ILDs) [e.g., Fueten et al., 2008; Okubo et al., 2008; Okubo, 2010], and not the regional distribution or orientation of small-scale deformational features within the chasmata. This study, which examines the orientations of small-scale deformational features visible within High Resolution Imaging Science Experiment (HiRISE) [McEwen et al., 2007] images of West Candor Chasma, is meant as a preliminary investigation of what mechanisms, if any, determine the orientations of small-scale deformational features in Valles Marineris.

\footnotetext{
${ }^{1}$ Department of Earth Sciences, Brock University, St. Catharines, Ontario, Canada.

${ }^{2}$ Pangaea Scientific, Brockville, Ontario, Canada.

${ }^{3}$ Institute of Planetary Research, German Aerospace Center, Berlin, Germany.

Corresponding author: F. Fueten, Department of Earth Sciences, Brock University, St. Catharines, ON L2S 3A1, Canada. (ffueten@brocku.ca)

(C)2012. American Geophysical Union. All Rights Reserved. 0148-0227/12/2012JE004144
}

[3] Within the Valles Marineris network of normal faultbounded troughs, displacement along large-scale, basinbounding normal faults (herein referred to as border faults), internal (buried) normal faults [Schultz and Lin, 2001] and pre-existing cross faults [Wilkins and Schultz, 2003], collectively referred to as chasma forming faults, accommodated the collapse that produced the linear troughs of Valles Marineris. The west-northwest border fault orientations [Schultz and Lin, 2001] are reflected by the consistent alignment of Coprates, Ius, Candor, and Ophir Chasma. Chains of pit craters such as Tithonia Catenae also exhibit this common orientation and have been thought to be the surface expression of either dike emplacement [Schultz, 1998], reactivation and lateral extension along border faults [Tanaka and Golombek, 1989; Wilkins and Schultz, 2003], or the result of regional or local extension [Wyrick et al., 2004]. Recent modeling by Smart et al. [2011] concludes that extensional fracturing and dilational normal faulting are the only viable mechanisms to produce pit chains.

[4] The troughs of Valles Marineris are up to $11 \mathrm{~km}$ deep [Lucchitta et al., 1994] and partially filled with younger, layered deposits, referred to as interior layered deposits [Malin and Edgett, 2000]. Deformational features documented within the ILD [e.g., Fueten et al., 2006, 2008; Okubo et al., 2008; Okubo, 2010] indicate these deposits are lithified to some degree. The lack of large mass wasting blocks, otherwise expected to accumulate beneath eroded outcrops of competent lithologies, may be attributed to fine grain sizes that allow ILD talus to break into small clasts when eroded [Malin and Edgett, 2000; Lewis et al., 2008]. 


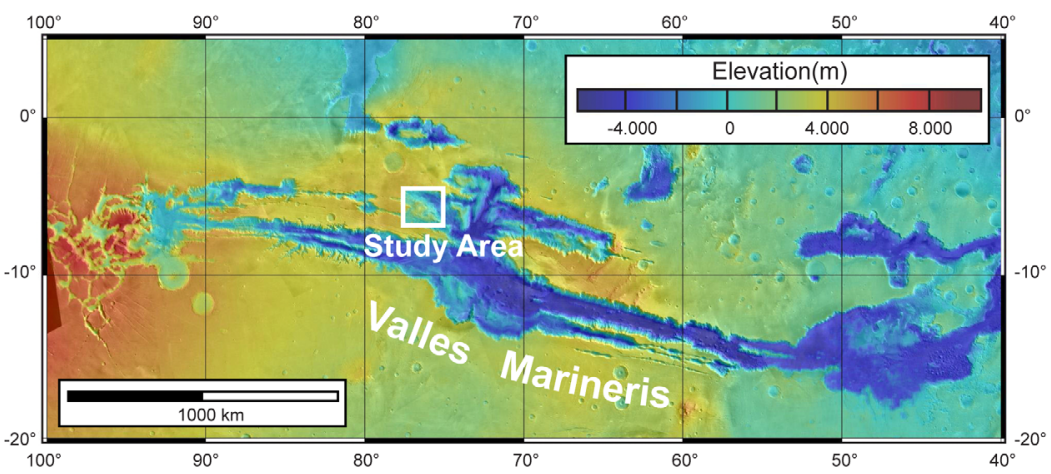

Figure 1. Location map of study area within Valles Marineris.

[5] Several authors have suggested structures such as pit chains [Blasius et al., 1977; Lucchitta, 1979, 1999; Spencer, 1983; Schultz, 1991; Lucchitta et al., 1992], fault scarps [Wilkins and Schultz, 2003] or orthogonal fracture sets [Fueten et al., 2008, 2010] observed in West Candor Chasma to be the result of late reactivation of the chasmaforming faults. Evidence for the imposed stresses which initiated a late reactivation of chasma-forming faults should be recorded by the orientations of small-scale deformational features within ILD. Small-scale fractures, like the ones measured here, have been shown to form on Earth, parallel to the maximum horizontal compressive stress [Rives et al., 1994; Caputo, 1995; Twiss and Moores, 2007].

[6] The study area is centered on Ceti Mensa, a large ILD at the western end of Candor Chasma (Figure 1). The area around Ceti Mensa has been extensively targeted by the HiRISE (Table 1) that has a maximum resolution of $\sim 25 \mathrm{~cm} /$ pixel, making it an ideal location to examine small-scale structures. The orientations of a large number of small-scale deformational features within the ILD of West Candor were examined to determine if they can provide insights into the geologic history of the ILD. Results show that their orientations display significant trends that can be related to the regional stress field and to movement along pre-existing cross-faults.

\section{Geologic Background}

[7] Valles Marineris is an approximately $4000 \mathrm{~km}$ long, network of fault-bounded troughs with a consistent NNWSSE orientation, located on the eastern margin of the Tharsis province, the largest and longest lived tectonic feature in the solar system [Golombek and Phillips, 2010]. The deformation of this region, following the emplacement of the plateauforming plains, began in the early Hesperian [Tanaka et al., 1991; Witbeck et al., 1991; Dohm and Tanaka, 1999] with the development of compressional structures called "wrinkle ridges" [Watters, 1993; Schultz, 2000], aligned concentrically about the Tharsis region. Wrinkle ridges are thought to be the surface expression of blind thrusts (or fault-propagation folds) [Plescia and Golombek, 1986; Schultz, 2000] accommodating compressional stresses induced by lithospheric loading of the Tharsis plateau [Banerdt et al., 1982; Sleep and Phillips, 1985]. Overprinting the wrinkle ridges are graben sets formed during the Late Hesperian to Early Amazonian [Tanaka et al., 1991; Mège and Masson, 1996;
Schultz and Fori, 1996], distributed radially around Tharsis and thought to be a consequence of flexural loading stresses related to lithospheric deformation [Banerdt et al., 1992; Wilson and Head, 2002]. Throughout the mid-Hesperian [Spencer and Fanale, 1990; Schultz, 1998], large segments of subsiding crust (on the order of $10 \mathrm{~s}$ of $\mathrm{km}^{2}$ ) formed isolated ancestral basins [Lucchitta and Bertolini, 1989; Witbeck et al., 1991; Lucchitta et al., 1992, 1994; Schultz, 1998; Fueten et al., 2006], which were later linked by broadening and elongation through faulting [Lucchitta et al., 1994; Schultz and Lin, 2001] during the late Hesperian-Amazonian [Schultz, 1998; Peulvast et al., 2001]. Recent modeling by Andrews-Hanna [2012a, 2012b] relates this latter deformation to isostatic readjustments where the Tharsis Rise overlies the crustal dichotomy boundary.

[8] Initial subsidence of crustal segments into the ancestral basins on the order of 3-5 $\mathrm{km}$ is reported by Lucchitta et al. [1994], while later fault-controlled subsidence may have lowered portions of Ius, Melas, Coprates, Candor and Ophir Chasmata to levels below older, adjacent ILD [Schultz, 1998]. Normal faults that bound the graben complex dip toward the centers of the troughs [Blasius et al., 1977; Masson, 1977, 1985; Lucchitta et al., 1992; Peulvast and

Table 1. List of HiRISE Images Used for This Study and Corresponding Letters on All Figures Using the CTX Mosaic of West Candor Chasma ${ }^{\text {a }}$

\begin{tabular}{|c|c|c|c|c|c|}
\hline Letter & $\begin{array}{c}\text { HiRISE Image } \\
\text { Number }\end{array}$ & Anaglyph & Letter & $\begin{array}{l}\text { HiRISE Image } \\
\text { Number }\end{array}$ & Anaglyph \\
\hline A & ESP $018374 \quad 1740$ & & $\mathrm{~L}$ & PSP $007232 \quad 1740$ & $\mathrm{X}$ \\
\hline \multirow[t]{2}{*}{ B } & PSP_002195_1745 & $\mathrm{X}$ & & PSP_007021_1740 & \\
\hline & PSP_002406_1745 & & M & PSP_009460_1745 & $\mathrm{X}$ \\
\hline $\mathrm{C}$ & PSP_002340_1735 & & & ESP_017741_1745 & \\
\hline \multirow[t]{2}{*}{ D } & PSP_001918_1735 & $\mathrm{X}$ & $\mathrm{N}$ & PSP_010238_1745 & $X$ \\
\hline & PSP_001984_1735 & & & PSP_008023_1745 & \\
\hline \multirow[t]{2}{*}{$\mathrm{E}$} & PSP_003540_1735 & $\mathrm{X}$ & & PSP_005386_1745 & \\
\hline & PSP_003474_1735 & & $\mathrm{O}$ & PSP_003263_1740 & \\
\hline $\mathrm{F}$ & ESP_013350_1745 & & $\mathrm{P}$ & PSP_002129_1735 & \\
\hline G & PSP_003329_1745 & & Q & PSP_002696_1745 & $\mathrm{X}$ \\
\hline $\mathrm{H}$ & ESP_015895_1745 & & & PSP_003197_1745 & \\
\hline \multirow[t]{2}{*}{ I } & PSP_002841_1740 & $\mathrm{X}$ & $\mathrm{R}$ & PSP_010093_1740 & $\mathrm{X}$ \\
\hline & PSP_003896_1740 & & & PSP_010515_1740 & \\
\hline $\mathrm{J}$ & PSP_002907_1745 & & $\mathrm{S}$ & TRA_000836_1740 & \\
\hline \multirow[t]{2}{*}{ K } & PSP_008814_1740 & $\mathrm{X}$ & $\mathrm{T}$ & PSP_009315_1745 & \\
\hline & ESP_016317_1740 & & $\mathrm{U}$ & PSP_003830_1740 & \\
\hline
\end{tabular}

${ }^{\mathrm{a}}$ The map projected scale of all the images is $25 \mathrm{~cm} /$ pixel. $\mathrm{X}$ denotes the images which compose an anaglyph set. 
Masson, 1993; Schultz, 1998; Peulvast et al., 2001; Schultz and Lin, 2001]. Displacement along steeply dipping border faults and interior buried faults (displacement on buried faults was minor relative to border faults) accommodated the roughly $6 \mathrm{~km}$ of vertical displacement necessary for the formation of Candor Chasma [Schultz and Lin, 2001]. The ratio of vertical subsidence to horizontal extension during the formation of the chasmata is high, resulting in limited extension and strain [Andrews-Hanna, 2012a, 2012b].

[9] Several troughs within Valles Marineris exhibit rectangular terminations for which different mechanisms have been proposed [e.g., Spencer and Fanale, 1990; Wilkins and Schultz, 2003]. The model proposed by Wilkins and Schultz [2003] to explain Candor Chasma's blunted terminations relies on pre-existing faults, oriented parallel to the principal extension trend of Valles Marineris (i.e., approximately $\mathrm{N}-\mathrm{S}$ ). Such faults could be pre-existing blind thrusts ascribed to wrinkle ridges, or normal faults involved in the formation of small graben [Wilkins and Schultz, 2003]. If, during N-S extension, border faults intersected one of these pre-existing faults, the latter fault would reactivate to form a cross-fault and enable normal displacement in the hanging walls of the border faults [Wilkins and Schultz, 2003].

[10] The normal faults bounding Candor Chasma [Wilkins and Schultz, 2003; Schultz and Lin, 2001] define trough walls (Figure 2a) with the following orientations. The western blunted terminations are defined by the Northern Cross Fault (NCF) and the Southern Cross Fault (SCF), both of which have a general trend of $\sim 40^{\circ}$. The southern boundary of Candor and the southern Tithonia Catenae pit chain are aligned along the Southern Border Fault (SBF), oriented at $107^{\circ}$. The Northern Border Fault (NBF) separating Candor and Ophir trends roughly $101^{\circ}$. The truncated central western wall that is aligned with the northern pit chain of Tithonia Catenae and an embayment of Ceti Mensa along a $105^{\circ}$ trend is designated the Central Border Fault (CBF). In Candor, as described above, pre-existing faults are inferred to have been reactivated within the hanging walls of the border faults and formed the cross faults (NCF and SCF) along the northern and southern blunted terminations [Wilkins and Schultz, 2003].

[11] Pit chains, oriented parallel to the main trend of Valles Marineris (e.g., Tithonia Catenae) and perpendicular to the NNE-SSW axis of extension, developed during the late Amazonian [Blasius et al., 1977; Lucchitta, 1979, 1999; Spencer, 1983; Schultz, 1991; Lucchitta et al., 1992]. They extend from the corners of Candor Chasma's blunted terminations where border and cross faults are assumed to intersect. It is during this episode of border fault motion, subsequent to the initial chasma opening, that reactivation and synchronous orthogonal extension [following Morewood and Roberts, $1997,2000,2001]$ of cross faults likely produced the blunted terminations observed in several chasmata (e.g., West Candor [Wilkins and Schultz, 2003]).

\subsection{Interior Layered Deposits}

[12] Layered deposits cover the chasma floors of Valles Marineris and have been eroded and deformed into a variety of landforms. ILDs cover $17 \%$ of the total area, representing $60 \%$ by volume of all deposits [Lucchitta et al., 1994] within Valles Marineris and display a variety of layer thicknesses, competencies and albedos. Layered units are classified into three general categories by Malin and Edgett [2000], based on layer thickness, albedo and configuration: a) "Massive" units are a few hundred meters to a few kilometers thick with poor to no bedding and are light- to intermediate-toned. b) "Layered" units are composed of hundreds of thin, tabular units with a wide range of thicknesses of up to $2000 \mathrm{~m}$. This relatively thin bedding is light- to intermediate-toned with a characteristic stair-stepped morphology. c) "Thin mesa" units are dark- to intermediate-toned, and usually unconformably overlie massive or layered units.

[13] Within West Candor, several kilometers of conformable stratigraphy are exposed with a major late unconformity below the uppermost units [Fueten et al., 2008]. The formation mechanisms responsible for such widespread deposits are still a matter of debate and it is unlikely a single process is responsible for the vast volumes of material and their associated landforms. The proposed processes of ILD deposition are: aqueous or subglacial volcanism [Komatsu et al., 2004; Lucchitta, 2004], exhumation of ancient material [Malin and Edgett, 2000; Catling et al., 2006], spring deposits [Rossi et al., 2008; Clarke and Bourke, 2009], subaerial volcanism [Komatsu et al., 2004], lacustrine [Nedell et al., 1987], aeolian [Peterson, 1981], pyroclastic volcanism [Lucchitta, 1987, 1990; Chapman, 2002; Hynek et al., 2003] and combinations thereof [Malin and Edgett, 2000].

[14] Investigation of layer attitudes [Beyer and McEwen, 2005; Fueten et al., 2006; Gaddis et al., 2006; Fueten et al., 2008] have determined that layers commonly dip in the direction of the topographic slope at a shallow angle $\left(<20^{\circ}\right)$. The extensive exposure and shallow dip has made lacustrine deposition a favored method of sedimentation [e.g., Komatsu et al., 2004; Fueten et al., 2006]. The diversity of attributes represented by ILD and their wide distribution indicate a variety of environment-specific processes are responsible for ILD formation.

[15] The ages of the ILD are also uncertain, though evidence suggests two possibilities. First, the assumed presence of ILD within the wall rock stratigraphy lead to the interpretation that deposition took place before the formation of Valles Marineris and recent deposition is limited to mantling material [e.g., Malin and Edgett, 2000, 2001; Catling et al., 2006]. Second, ILD distribution and structural mapping supports deposition during and/or after the formation of the ancestral basins [e.g., Lucchitta, 1990, 1999; Witbeck et al., 1991; Lucchitta et al., 1994; Schultz, 1998; Chapman and Tanaka, 2001; Fueten et al., 2006, 2008; Okubo et al., 2008; Okubo, 2010]. In recent years, the latter interpretation (i.e., post- and/or syn-subsidence deposition) has become the favored model of ILD emplacement. Layered material comprising Ceti Mensa and other large isolated ILDs were suggested to have been deposited in isolated subbasins and acquired their current configuration by differential subsidence rates and magnitudes of ILDs and surrounding terrain [Fueten et al., 2008].

\subsection{Ceti Mensa}

[16] Ceti Mensa, an ILD encompassing an area of more than $2500 \mathrm{~km}^{2}$ reaches heights of more than $5 \mathrm{~km}$ above the surrounding chasma floor [Gaddis et al., 2006; Lucchitta, 2007] and lies at the center of our study area in West Candor (Figures 2a and 2b). Two domal edifices, separated by an NE-SW trending trough, are bordered by several 


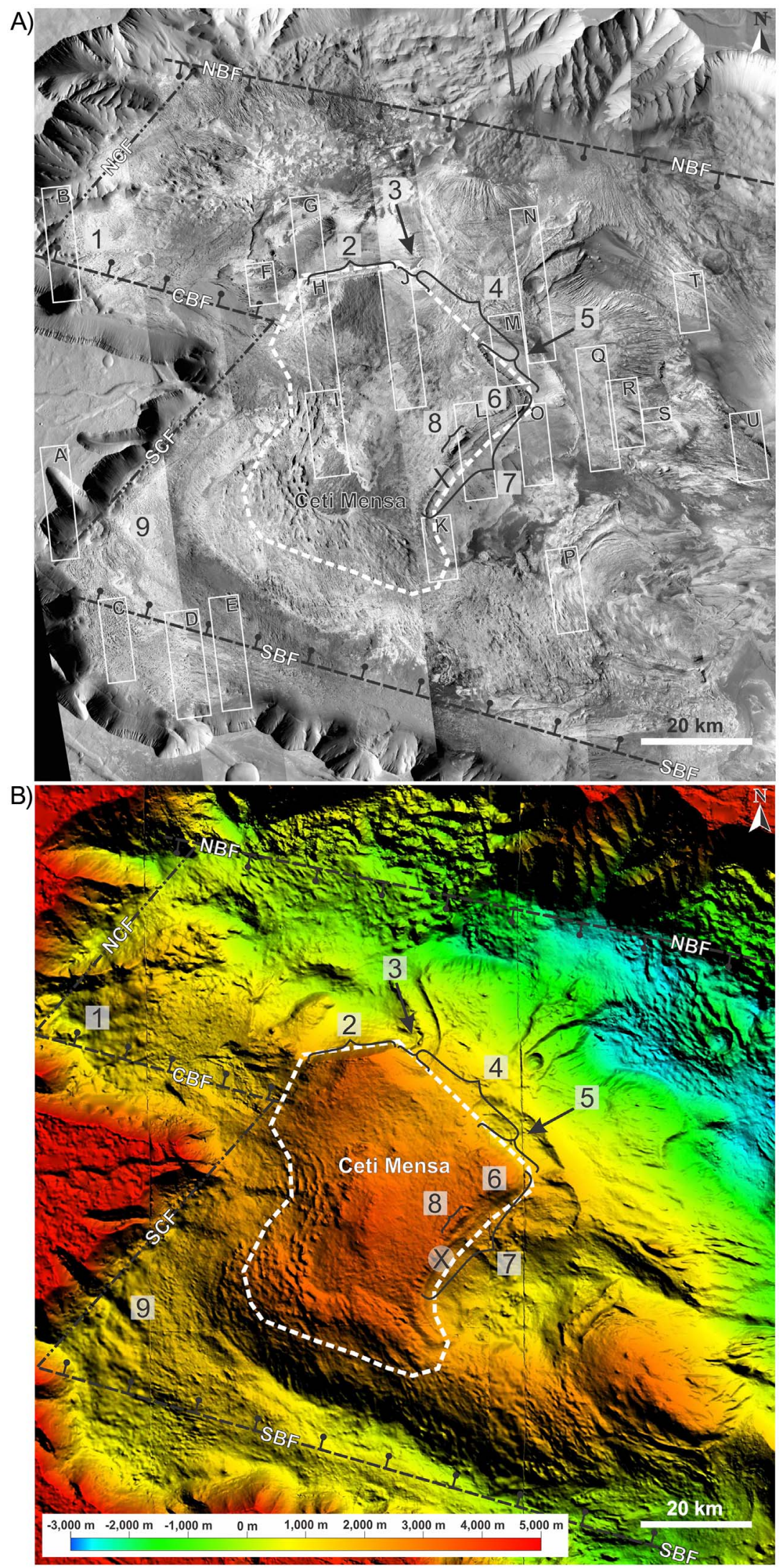

Figure 2 


\section{Deflection of Non-Vertical Fractures}

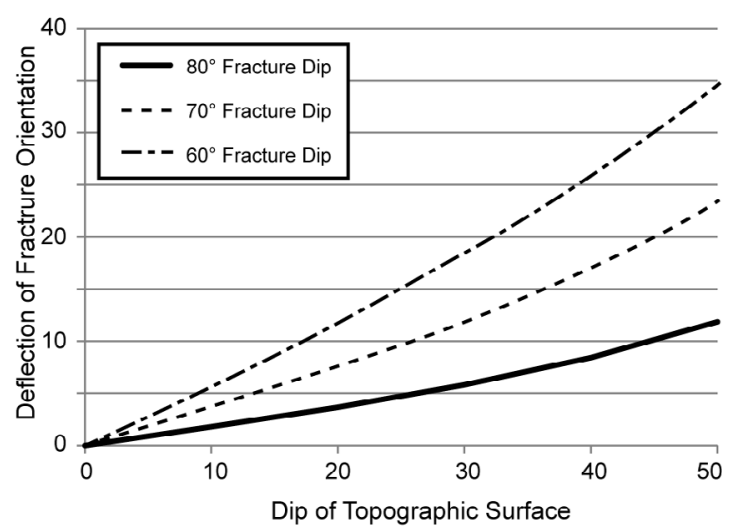

Figure 3. Graph of topographic slope versus deflection of the recorded fracture orientation from the actual strike for various fracture dips.

scarps of $650 \mathrm{~m}$ to more than $1500 \mathrm{~m}$ of relief locally and expose a range of inclined layers. Both the northern (Figures 2a and 2b, Feature 2) and southeast border scarps (Figures 2a and 2b, Feature 7) are defined by two deeply incised, rounded re-entrants (Figures $2 \mathrm{a}$ and $2 \mathrm{~b}$, Features 3 and 5) [Lucchitta, 2007]. The southeast border scarp is oriented at $40^{\circ}$, parallel to the western blunted terminations of Candor (Figures $2 \mathrm{a}$ and $2 \mathrm{~b}$, Features 1 and 9). The northeast border (Figures $2 \mathrm{a}$ and $2 \mathrm{~b}$, Feature 4 ), oriented $\sim 124^{\circ}$, is bifurcated by chaotic material sliding/flowing northward off Ceti Mensa. To the northwest, it is truncated by a normal fault (Figures 2a and 2b, Feature 2) $16 \mathrm{~km}$ long, striking $263^{\circ}$ with at least $1.4 \mathrm{~km}$ of displacement and dips ranging from $28^{\circ}$ and $36^{\circ}$ [Fueten et al., 2007].

\subsection{Deformation of Interior Layered Deposits}

[17] Deformation of ILDs by faulting [Okubo and McEwen, 2007; Fueten et al., 2008; Okubo et al., 2008; Okubo, 2010] and fracturing [Fueten et al., 2008; Okubo, 2010] has previously been documented in West Candor. Structural observations of ILDs by Fueten et al. [2008] in West Candor Chasma demonstrate that certain prominent trends of fractures and other surface features are consistent throughout the area and may reflect underlying faults. In their study area directly adjacent ours, two regional trends approximately parallel to the southern and western borders of the chasma were displayed by fault scarps, fractures and linear depressions.
[18] In the southwest corner of our study area, Okubo et al. [2008] attempted to determine the relative age of ILD by identifying chasma-forming faults within them. They observe no strike-slip faults and no faults (thrust or normal) of sufficient size or appropriate orientation exposed at the surface to be categorized as chasma-forming faults. The average trend of $62^{\circ}$ for normal faults in their study area is inconsistent with the predicted $110^{\circ}$ orientations suggested by Schultz and Lin [2001]. They conclude that the material within their study area represents mass-wasted (slump) material along a south-facing slope (movement is to the south), similar to the present topography. Later work in the same area by Okubo [2010] determined a population of subvertical joints (average trend of approximately $108^{\circ}$, average dip of $80^{\circ} \pm 5^{\circ}$ ), consistent with minor chasma subsidence, to be the most recent deformational features in the area.

\section{Methodology}

[19] Seven Context Camera (CTX) [Malin et al., 2007] images were registered to High Resolution Stereo Camera (HRSC) elevation data of West Candor using Global Mapper (GIS/GPS mapping) software to construct a base map mosaic of the study area. Thirty-two HiRISE images were examined for this study and their locations recorded on the CTX mosaic to provide a context in which to view the measured orientations for each HiRISE image (Figure 2a). Within each image faults and different types of fractures, discussed in detail below were measured. Faults were identified by a visible offset across the zone, while fractures may display dilation but no obvious offset. The azimuth of the horizontal projection of the fracture trace will henceforth be referred to as the fracture's "orientation." All orientations were measured in plan view directly from HiRISE images using a digital on-screen protractor and were not corrected for the topographic slope because the fractures are assumed to be vertical. This assumption is reasonable because fractures are generally linear, even when formed in uneven topography and form steeply dipping cliff faces, despite the subsequent effects of erosion. The attitudes of joints measured in the south of our study area by Okubo [2010] of $80^{\circ} \pm 5^{\circ}$ also agree with this assumption. The orientations of vertical fractures are equal to their strike and give useful information about the stress orientations present during their formation. For reasonably shallow slopes, such as those observed in the study area (maximum slope $\sim 35^{\circ}$ ), the deflection generated by a non vertical $\left(>60^{\circ}\right)$ fracture is minimal, less than about $20^{\circ}$ (Figure 3 ). We do not know the full $3 \mathrm{D}$ extents of the fractures which does limit somewhat

Figure 2. (a) Labeled map of West Candor Chasma with Ceti Mensa outlined by thick white broken line: (1) Northwest blunted termination of Candor Chasma, (2) Northern border scarp of Ceti Mensa, (3) Northern re-entrant into Ceti Mensa, (4) Northeast border of Ceti Mensa, (5) Eastern re-entrant into Ceti Mensa, (6) Eastern prominence, (7) Southeast border scarp of Ceti Mensa, (8) Large discrete scarp, (9) Southwest blunted termination of Candor Chasma. X denotes the location shown in Figure 11. Letters in the top right corner of each HiRISE image location, defined by white boxes, correspond to Table 1. The proposed locations of large scale underlying border faults of Schultz and Lin [2001] are indicated by dashed lines with the bar and ball symbols on the on the hanging wall side of the faults $(\mathrm{NBF}=$ Northern Border Fault; $\mathrm{CBF}=$ Central Border fault; SBF = Southern Border fault). The cross fault locations proposed by Wilkins and Schultz [2003] are represented by a dash and two dots without a symbol designating the hanging wall (NBF $=$ Northern Border Fault; SCF = Southern Border Fault). (b) Labeled High Resolution Stereo Camera (HRSC) [Jaumann et al., 2007] digital terrain model (DTM) composite of West Candor Chasma. 
Table 2. Comparison of the Dominant Fracture Orientations, From Different Parts of the Study Area, and the Corresponding Surface Dip Direction to Determine if a Relationship Exists Between the Two Values ${ }^{\mathrm{a}}$

\begin{tabular}{|c|c|c|c|c|}
\hline HiRISE Image & $\begin{array}{l}\text { Image } \\
\text { Letter }\end{array}$ & $\begin{array}{l}\text { Dominant } \\
\text { Fracture } \\
\text { Orientation } \\
\left(0^{\circ}-180^{\circ}\right)\end{array}$ & $\begin{array}{l}\text { Average Strike/ } \\
\text { Dip of Surface }\end{array}$ & $\begin{array}{c}\text { Difference } \\
\text { Between } \\
\text { Average } \\
\text { Orientation } \\
\text { and Strike } \\
\left(0^{\circ}-90^{\circ}\right)\end{array}$ \\
\hline ESP_013350_1745 & $\mathrm{F}$ & 109 & $155 \pm 15 / 05 \pm 1$ & 46 \\
\hline PSP_003329_1745 & G & 155 & $275 \pm 18 / 05 \pm 2$ & 60 \\
\hline PSP_003329_1745 & $\mathrm{G}$ & 25 & $174 \pm 16 / 11 \pm 3$ & 31 \\
\hline PSP_002841_1740 & $\mathrm{I}$ & 115 & $172 \pm 14 / 16 \pm 4$ & 57 \\
\hline PSP_007232_1740 & $\mathrm{L}$ & 54 & $049 \pm 9 / 11 \pm 2$ & 5 \\
\hline PSP_002696_1745 & Q & 26 & $079 \pm 9 / 07 \pm 1$ & 53 \\
\hline PSP_002696_1745 & Q & 96 & $297 \pm 6 / 09 \pm 1$ & 21 \\
\hline PSP_002696_1745 & Q & 31 & $109 \pm 5 / 11 \pm 1$ & 78 \\
\hline ESP_015895_1745 & $\mathrm{H}$ & 88 & $298 \pm 13 / 04 \pm 1$ & 30 \\
\hline ESP_015895_1745 & $\mathrm{H}$ & 46 & $030 \pm 20 / 01 \pm 0$ & 16 \\
\hline PSP_007232_1740 & $\mathrm{L}$ & 54 & $191 \pm 23 / 02 \pm 1$ & 43 \\
\hline PSP_002841_1740 & I & 107 & $190 \pm 6 / 11 \pm 1$ & 83 \\
\hline ESP_013350_1745 & $\mathrm{F}$ & 108 & $129 \pm 12 / 11 \pm 3$ & 21 \\
\hline ESP_013350_1745 & $\mathrm{F}$ & 43 & $124 \pm 8 / 20 \pm 2$ & 81 \\
\hline ESP_013350_1745 & $\mathrm{F}$ & 119 & $124 \pm 8 / 20 \pm 2$ & 5 \\
\hline
\end{tabular}

${ }^{\mathrm{a}}$ Fracture orientations were measured from $0^{\circ}$ to $180^{\circ}$ while the strike and dip of the surface was recorded using right hand rule from $0^{\circ}$ to $360^{\circ}$. The strike value was then converted to a commensurate value from $0^{\circ}$ to $180^{\circ}$ and the difference between the two measurements was expressed as a value from $0^{\circ}$ to $90^{\circ}$.

the interpretations based on the terrestrial examples and laboratory models.

[20] The maximum resolution of the HiRISE images used for this study is $25 \mathrm{~cm} /$ pixel, requiring the aperture dimensions of deformational features (faults and fractures) to be of that scale for them to be visible. Measurements of smallscale faults and fractures could only be made in areas covered by HiRISE images (unless otherwise noted) and are therefore inevitably biased by the location of the available HiRISE images.

\subsection{Fracture Orientation and Local Slope}

[21] To determine if the fracture orientations show any relationship to the directions of the topographic slope, HRSC digital elevation models 0360_0000 (100 m/pixel) and 0334_0000 (100 m/pixel) and Orion structural analysis software (www.pangaeasci.com) were used to compare fracture orientations with local topography at 15 locations (Table 2). Orthogonal fractures are the most common fractures observed and were therefore selected for this analysis. The difference between local surface strike direction and dominant fracture orientation was calculated as a value between 0 and $90^{\circ}$.

\subsection{Fracture Orientation and Elevation}

[22] The formation of fracture systems may be strongly controlled by the mechanical properties of the rock [e.g., Lorenz et al., 2002]. Previously mapped units are either defined on a broad regional scale [Witbeck et al., 1991] or the mapped region does not cover the entire study area [Lucchitta, 1999]. Gaddis et al. [2006] describe 5 major units on Cetis Mensa and suggest that their occurrence is limited to ranges in elevation. The measured dip of layering in the area is shallow [e.g., Fueten et al., 2007, 2008] and therefore elevation can be used as a proxy for stratigraphic level (assuming no differential vertical displacement of equivalent units). For each measurement location, defined as a sub-area within a single HiRISE image, the average orientation of the dominant orthogonal fracture set (see section 4.1) was recorded, along with the average elevation for that location. The average elevation was used because the HRSC DTM resolution for this area is only $50-100 \mathrm{~m} /$ pixel and the elevation of individual deformational features cannot be resolved.

\subsection{Data Presentation}

[23] To examine the orientation trends displayed by different types of fractures, orientation data for individual fractures of the same type were plotted on circular histograms using the SpheriStat orientation analysis software (www. pangaeasci.com). A Gaussian smoothing was applied to compensate for the small number of data points collected in some areas. Data with a unimodal distribution were given a class interval so that the expected frequency value was equal to or greater than the standard deviation [Robin and Jowett, 1986]. For very small data sets $(\mathrm{N}<7)$, it was sometimes impossible to achieve expected values less than the standard deviation even with the maximum class interval size of $45^{\circ}$. When graphing a clearly multimodal data set, a class interval which preserved the individual modal characteristics was used.

[24] For HiRISE images that transect the borders of Ceti Mensa (HiRISE images $\mathrm{K}$ and L), two histograms were produced to display data from on top of and below Ceti Mensa accordingly. For HiRISE images J, M and O, where only a small portion of the image transects the border, the entirety of the data was collected in the area represented by the bulk of the image. Data for HiRISE image A, which transects the chasma floor, wall rock and plateau, was only gathered from chasma floor and the base of the wall rock and is represented by a single histogram.

\section{Descriptions of Deformational Features}

\subsection{Orthogonal Fractures}

[25] Orthogonal fractures sets (Figure 4a) are composed of a dominant set and an orthogonally oriented secondary set. Both the dominant and secondary sets are extensional features composed of parallel to sub-parallel planar fractures with similar spacing. The lengths of the dominant fractures are greater than four times the spacing between the members of the dominant set. Roughly orthogonal to the dominant set are the secondary fractures with short lengths, typically defined by the spacing between the members of the dominant fracture set. Secondary fractures generally terminate (abut) against the dominant fractures. In some areas, secondary fractures do transect dominant fractures but their lengths are less than four times the spacing of the dominant set. Relative to the dominant fractures, the orientations of the secondary fractures are more variable. The intersection of the dominant and secondary fractures produces an equant to elongated rhombic pattern in plan view.

[26] Previous work on the propagation of orthogonal fractures sets in terrestrial settings [e.g., Rives et al., 1994; Caputo, 1995; Bai et al., 2002] have proposed that the 

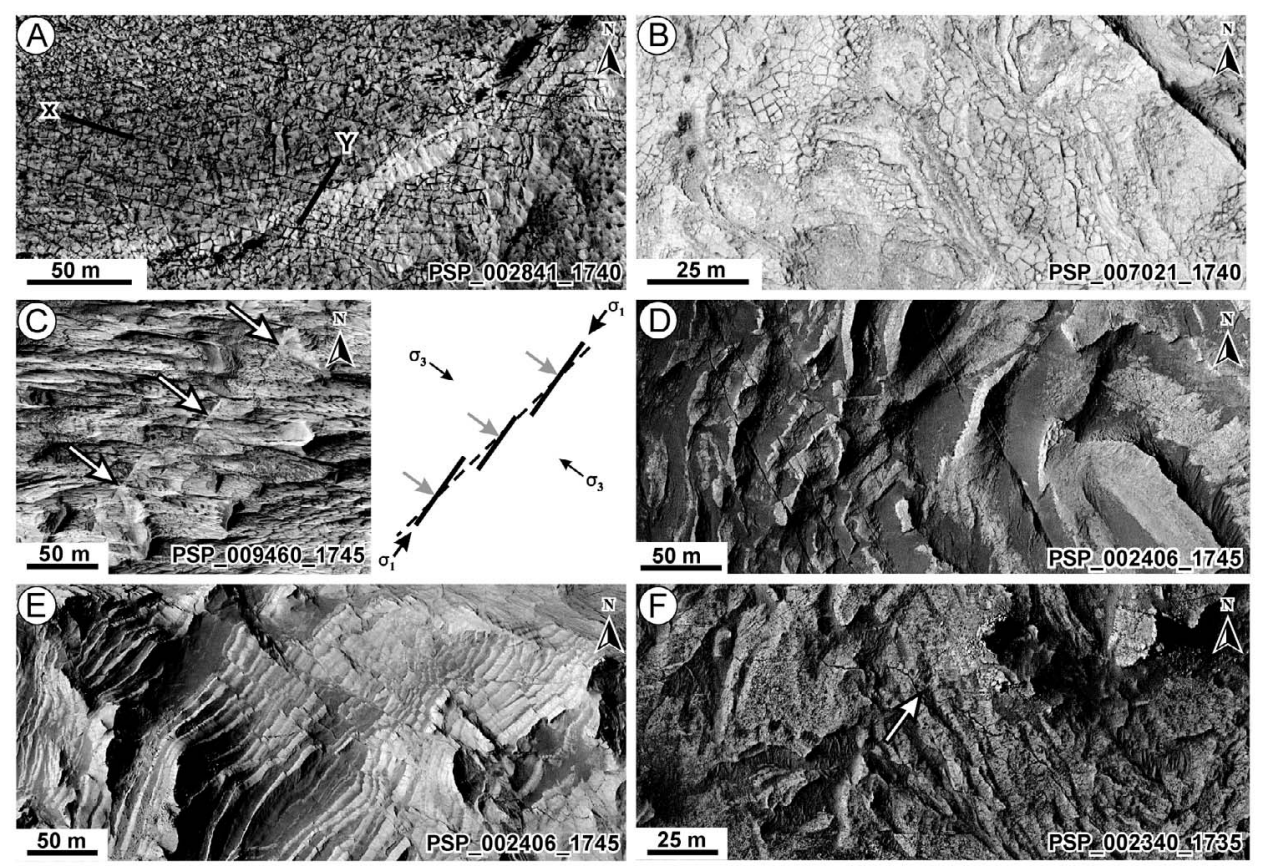

Figure 4. (a) Orthogonal fractures: $\mathrm{X}=$ Dominant fracture set, $\mathrm{Y}=$ Secondary fracture set (HiRISE image I). (b) Irregular polygons (HiRISE image L). (c) En echelon fracture set (HiRISE image M) and gash fracture formation model modified from Twiss and Moores [2007]. White arrows point to individual fractures within the en echelon array and correspond to the gray arrows. The dashed line shows the orientation of the shear zone, $\sigma_{1}$ is the direction of the maximum horizontal compressive stress and $\sigma_{3}$ is the direction of the minimum horizontal compressive stress. (d) Unidirectional fracture set (HiRISE image B). (e) Faults offsetting layered material (HiRISE image B). (f) Curved fracture within relatively flat topography (HiRISE image C).

dominant set forms first, parallel to the maximum horizontal compressive stress (i.e., perpendicular to the maximum tensile stress). After the dominant set forms, if a second stress is applied orthogonal or oblique to the initial stress, a secondary fracture set abutting the dominant fractures will form. The source of the secondary stress may result from one of a variety of sources such as orthogonal loading or visco-elastic relaxation [Rives et al., 1994]. Visco-elastic relaxation displays both viscous and elastic properties, producing timedependant strain in the affected material [Twiss and Moores, 2007]. In orthogonal fracturing, visco-elastic relaxation allows for the gradual release of the initial stress, producing a tension normal to the initial extension, causing a secondary fracture set to develop progressively during relaxation [Rives et al., 1994].

[27] A mutually crosscutting relationship may occur if either the secondary stress is greater than the initial stress or the initial fractures are closed (healed) when the secondary stress is applied [Rives et al., 1994]. In general, only one fracture orientation is dominant and the fractures orthogonal to it are secondary. However, when the conditions previously discussed are satisfied and a mutually crosscutting relationship is established, both orientations were recorded as being dominant.

[28] Superficially, regions with orthogonal fractures may appear similar to polygonally patterned ground reported poleward of $55^{\circ}$ latitude on Mars [Mangold et al., 2004] and formed through a combination of processes. Thermal contraction or desiccation of sediments can produce small, irregular fractures which are then progressively widened, elongated and interconnected by sediment infilling [Sletten et al., 2003]. Irregular polygons (Figure 4b) were excluded from our measurements as they do not fall within the categories specified for this study.

\subsection{En Echelon Fracture Sets}

[29] En echelon fracture sets are composed of multiple fractures with nearly parallel orientations in an apparent en echelon pattern and roughly equal offset, either left or right stepping indicating the sense of shear (Figure 4c). En echelon fractures appear similar to gash fractures [Twiss and Moores, 2007] that have not undergone ductile shear and are assumed to have similar origins. Gash fractures are extensional features that form during shearing, the fractures being parallel to the maximum horizontal compressive stress and oblique to the orientation of the shear zone [Twiss and Moores, 2007]. With this in mind, the orientations of individual fractures within an en echelon array were recorded to document the maximum horizontal compressive stress direction. The overall trend representing the shear zone orientation is reported in Table 3.

\subsection{Unidirectional Fractures}

[30] Unidirectional fractures are described as parallel to sub-parallel linear fracture sets with similar spacing but not occurring in conjunction with a secondary fracture orientation. These fractures can be thousands of meters long, but are generally tens to hundreds of meters long (Figure 4d) and 
Table 3. En Echelon Fracture Orientations, Shear Zone Orientations and Sense of Shear ${ }^{\mathrm{a}}$

\begin{tabular}{cccc}
\hline $\begin{array}{c}\text { HiRISE Image } \\
\text { Letter }\end{array}$ & Shear Sense & $\begin{array}{c}\text { Fracture } \\
\text { Orientation }\end{array}$ & $\begin{array}{c}\text { Shear Zone } \\
\text { Orientation }\end{array}$ \\
\hline H & Left stepping & 139 & 135 \\
J & Left stepping & 45 & 33 \\
L & Left stepping & 42 & 29 \\
L & Left stepping & 22 & 19 \\
M & Left stepping & 17 & 11 \\
M & Left stepping & 27 & 26 \\
M & Left stepping & 36 & 33 \\
T & Left stepping & 29 & 23 \\
E & & & \\
E & Right stepping & 180 & 7 \\
L & Right stepping & 11 & 17 \\
L & Right stepping & 35 & 50 \\
L & Right stepping & 35 & 43 \\
L & Right stepping & 54 & 76 \\
M & Right stepping & 50 & 52 \\
M & Right stepping & 26 & 40 \\
Right stepping & 32 & 46 \\
\hline
\end{tabular}

${ }^{a}$ All measurements in HiRISE image $\mathrm{L}$ are from below the southeast border scarp.

show no evidence of shear displacement. According to Engelder and Geiser [1980], such fractures on Earth are form parallel to the maximum horizontal compressive stress.

\subsection{Faults}

[31] Faults were defined by an observable apparent horizontal offset in layering or a scarp morphology only, and do not include more complex faults requiring detailed structural mapping for identification (Figure 4e). As only the apparent offset of the faults were visible, the true offsets could not be determined and only their orientation was recorded.

\subsection{Curved Fractures}

[32] Fractures that display an irregular or curved trace are designated curved fractures. Since the curvature is readily apparent in essentially flat topography, the curvature is not the result of a topographic cut effect. They were measured by visually estimating a straight line of best fit that accommodates their variable orientations. The curved profiles are consistent with extensional fractures formed by longitudinal splitting and not the result of topography and a low dip angle (although it may have accentuated the curvature). Material factors such as variations in tensile strength encouraging propagation along the path of lowest energy or the coalescing of individual fractures may also have played a role in creating their curved profile. Fractures with an overall curve to their trace in plan view may have experienced a rotation of local stresses during their formation, although the source of such rotation is unknown. Curved fractures are the only fracture type recorded that does not occur in parallel sets (Figure 4f).

\section{Results}

\subsection{Topographic and Stratigraphic Effects on Fracture Orientation}

[33] The differences between the local average dominant fracture orientation and the local slope direction reported in Table 3 are highly variable. We argued earlier that the elevation of the data can serve as a first order proxy to the stratigraphy. Measured deformational features are recorded over a range of elevations from $-2608 \mathrm{~m}$ to $3217 \mathrm{~m}$. Sorting all data by the elevation (Figure 5) indicates that data are available over a continuous range of elevations from 155 to $3217 \mathrm{~m}$, with few observations between $155 \mathrm{~m}$ and $-2608 \mathrm{~m}$ (Figure 5). Orientation versus elevation graphs for individual fracture types are provided below (Figure 6). In the graph of dominant fracture orientations versus elevation, two clusters of data for the $120^{\circ}$ orientation are observed at $\sim 1600 \mathrm{~m}$ and $\sim 3000 \mathrm{~m}$. The curved and unidirectional fracture data is diffusely distributed but a bias for $3000 \mathrm{~m}$ is again present in both. However, the clustering of data along a given elevation, for a wide range of orientations, may indicate a sampling bias (many orientations measured in the same location and therefore with a similar elevation) and not a significant relationship between the elevation and orientation. The small sample size for the en echelon fractures does not provide enough data to draw any definitive conclusions.

\subsection{Cumulative Fracture Data}

[34] Where not obscured by dunes or mantling cover, faults and fractures can be observed throughout West Candor. Fracture abundance gradually diminishes to the east of Ceti Mensa due in large part to greater volumes of obscuring material. A data set incorporating the orientations of 683 faults, 3114 orthogonal fractures, 1027 unidirectional fractures, 286 curved fractures and 16 en echelon fracture sets (Figure 7, images A-K) was compiled.

[35] Figure 7 displays the cumulative histograms for individual fracture types. Throughout the study area, orthogonal fractures predominate. Both the dominant and secondary orthogonal fracture histograms (Figure 7, images A, B, and C) show two prominent regional trends of $20^{\circ}-40^{\circ}$ and $100^{\circ}-$ $125^{\circ}$. A secondary peak between $60^{\circ}$ and $80^{\circ}$ is also present in the dominant fracture histogram but not in the secondary fracture histogram.

[36] En echelon fractures display a very strong trend of $25^{\circ}-55^{\circ}$ parallel to the cross faults but the data set is quite small (Figure 7, image D).

[37] The cumulative histogram for curved fractures (Figure 7, image E) reveals a wide distribution of orientations from $1^{\circ}$ to $180^{\circ}$, but with three slightly larger populations,

Elevation vs. Orientation

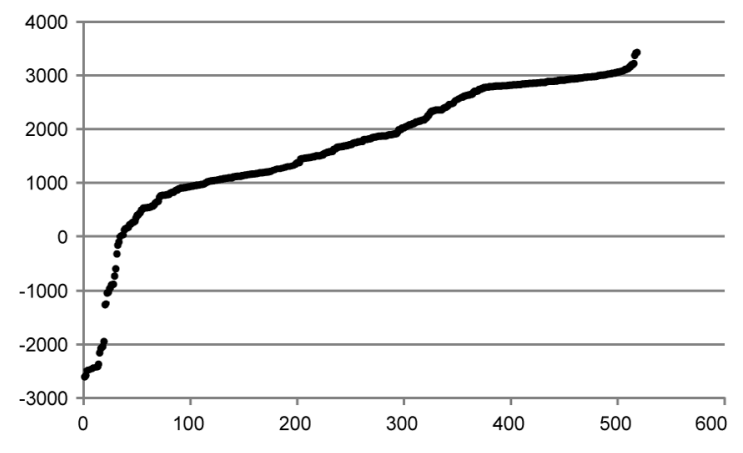

Figure 5. Distribution of elevations at which orientation data was recorded. All available measurement elevations are sorted by elevation to simply indicate at which elevations data was available. 


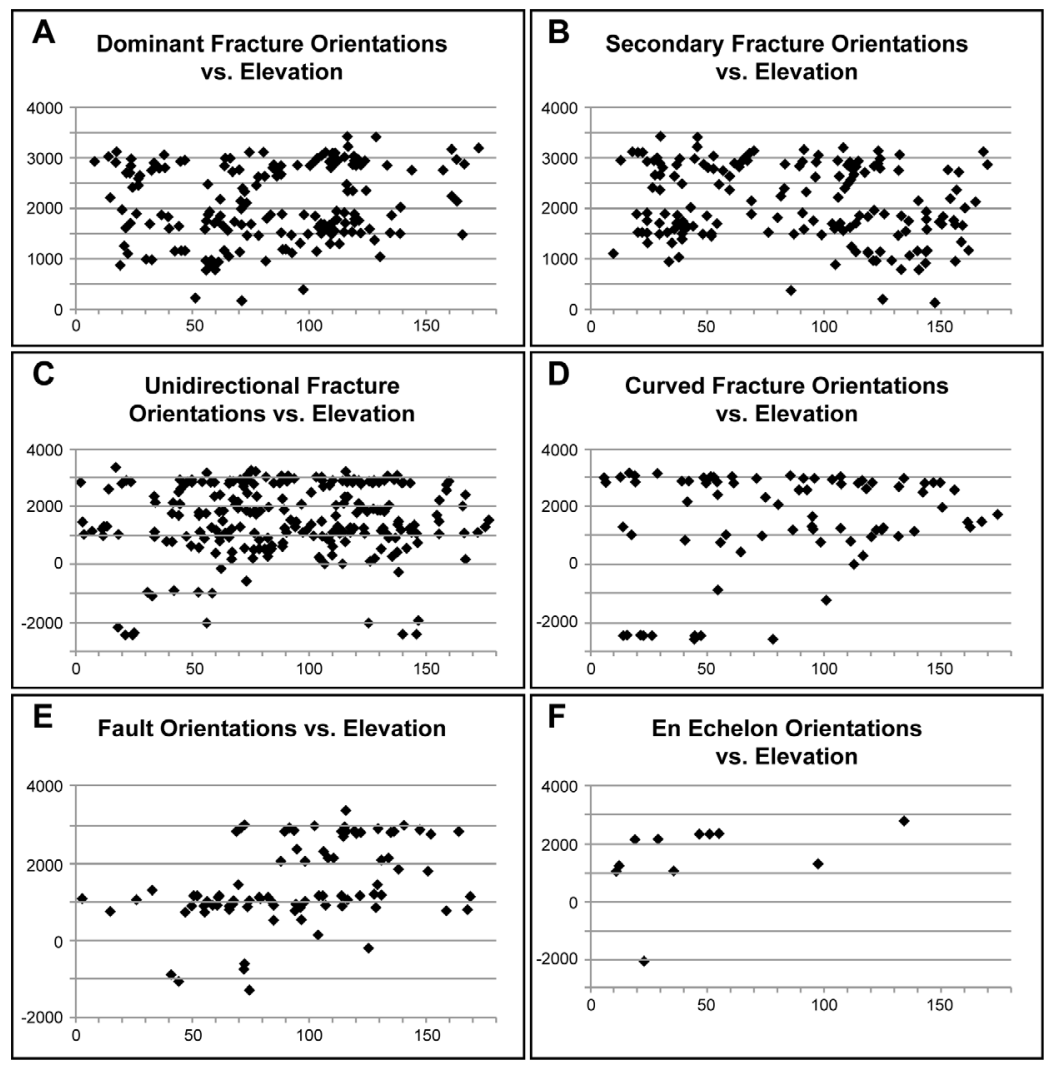

Figure 6. Distributions of elevations at which orientation measurements for individual deformational feature types are recorded.

two at right angles to each other of $25^{\circ}-35^{\circ}$ and $115^{\circ}-135^{\circ}$ and one of $10^{\circ}-15^{\circ}$.

[38] A prominent trend of $72^{\circ}$ is observed for faults (Figure 7, image F). When the orientations of the faults in the SW (HiRISE images C, D, and E), proposed by Okubo et al. [2008] to be slump material, are removed, this trend becomes more defined and two other trends of $115^{\circ}-125^{\circ}$ and $135^{\circ}-155^{\circ}$ become prominent (Figure 7, image G). The faults in images $\mathrm{C}, \mathrm{D}$ and $\mathrm{E}$ also display a prominent orientation trend of $70^{\circ}$ but do not display an abundance of the $115^{\circ}-125^{\circ}$ and $135^{\circ}-155^{\circ}$ orientations (Figure 7 , image $\mathrm{H}$ ).

[39] The cumulative histogram for unidirectional fractures (Figure 7, image I) shows a wide distribution within the study area but with a slight peak for $70^{\circ}-80^{\circ}$ orientations. By removing the unidirectional fractures from the SW slump material this trend becomes less prominent and two trends of $110^{\circ}-120^{\circ}$ and $\sim 140^{\circ}$ stand out (Figure 7 , image J). The unidirectional fracture data from HiRISE images C, D and E (Figure 7 , image $\mathrm{K}$ ) display two clearly preferred orientations which include the $\sim 65^{\circ}-75^{\circ}$ and $110^{\circ}-120^{\circ}$ previously described for all unidirectional fractures and the dominant orthogonal fractures respectively. Local orientation trends for each fracture type are discussed below and presented separately in Figures 8, 9, 12, 13, 15, and 16.

\subsection{Orthogonal Fractures}

[40] Near the inferred intersection of the CBF and SCF along the western margin of Ceti Mensa, areas of orthogonally fractured material, both atop western Ceti Mensa and in the surrounding lowlands (Figures 8 and 9, images F, G,
$\mathrm{H}$, and I), display two principal orientations of roughly $105^{\circ}-120^{\circ}$ and $20^{\circ}-30^{\circ}$. Both the dominant and secondary fracture sets display these well-defined, preferred orientations and account for $47 \%$ of all the orthogonal fractures in the area.

[41] Toward the center of southern Ceti Mensa (Figures 8 and 9, image I), the principal orientation of the secondary fracture set trends $10^{\circ}-30^{\circ}$, i.e., sub-parallel to the cross fault orientation, and the dominant fracture set has a distinct $105^{\circ}-120^{\circ}$ trend parallel to the border faults. In north central Ceti Mensa (Figures 8 and 9, image J), large regions of extensively fractured material are present but do not exhibit clearly defined dominant and secondary fracture sets. Instead, fractures have multiple orientations and produce irregular polygons.

[42] Below much of Ceti Mensa's southeast border scarp, a layer of unfractured high albedo material covers the chasma floor. In places however, fractures are faintly visible underneath a thin covering (Figure 10) or have not been covered and are clearly visible. Where orthogonal fractures are discernible below the southeast border scarp (Figures 8 and 9, image L) and to the east of the eastern prominence (Figures 8 and 9, images $\mathrm{O}$ and $\mathrm{Q}$ ), two strong orientations of $20^{\circ}-65^{\circ}$ and $105^{\circ}-145^{\circ}$ were recorded in both fracture sets. The extent of the orthogonal fractures exhibiting these orientations spans the entire length of the scarp with only one exception. Secondary fractures recorded below the southeast border scarp within Figure 9 (image L) display a strong bimodal distribution of $20^{\circ}-35^{\circ}$ and $130-145^{\circ}$. The $130^{\circ}-145^{\circ}$ trend is parallel to one set of large unidirectional 

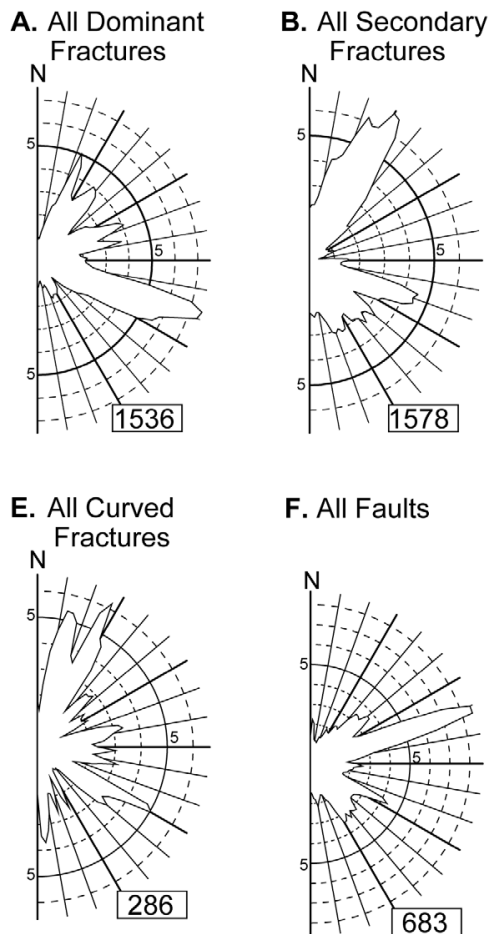

F. All Faults

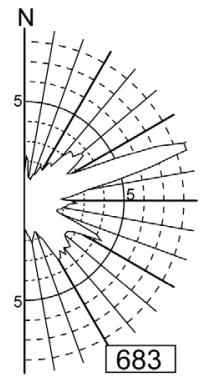

I. All Unidirectional Fractures

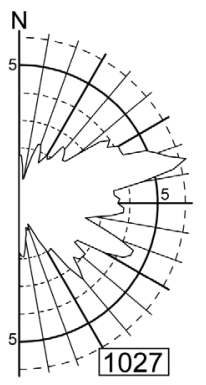

J. All Unidirectional Minus C, D \& E

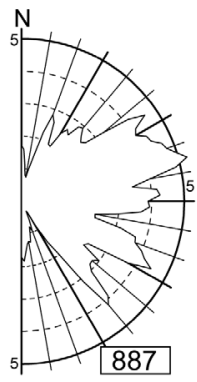

C. All Dominant and
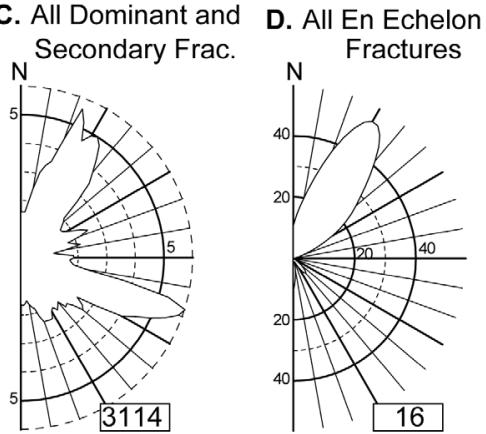

G. All Faults Minus C, D \&E Faults

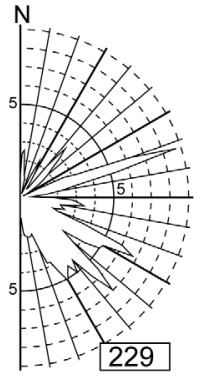

\section{H. Faults From $C, D$ \&}

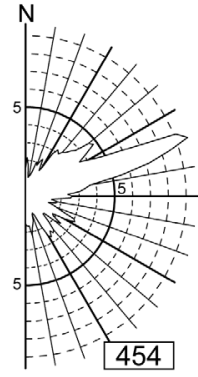

K. Unidirectional Fractures

From C, D \& E

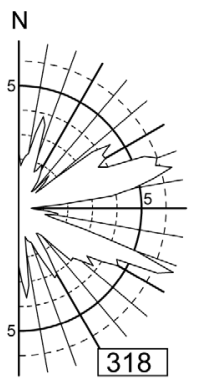

Figure 7. Cumulative histograms for all fracture types. The data collected from HiRISE images C, D and $\mathrm{E}$ has been presented separately for the faults and unidirectional fractures. The "All Dominant and Secondary" histogram is just a composite of the All Dominant and All Secondary histograms.

fractures visible in CTX image P16 007232 XN 05S076W $(5.44 \mathrm{~m} / \mathrm{pixel})$ immediately to the west of this location (Figure 11). These large fractures are visible along Ceti Mensa's southeast border scarp trending $\sim 140^{\circ}$ and dissect only the upper layered units. A few of the large unidirectional fractures appear to intersect a less well developed fracture set trending $\sim 80^{\circ}$ (Figure 11, image Y), producing angular outcrops.

[43] Within the eastern re-entrant (Figures 8 and 9, image M), two orthogonal fracture sets within high albedo material display four strong trends. The larger set with a broader peak trends $60^{\circ}-75^{\circ}$ (dominant set) and $135^{\circ}-160^{\circ}$ (secondary set) while the second, smaller, well defined set trends $57^{\circ}-$ $62^{\circ}$ (dominant) and $98^{\circ}-101^{\circ}$ (secondary). In areas where both orthogonal fracture sets are present, irregular polygons are formed. The dominant fractures of the smaller well- defined trend crosscut both the dominant and secondary fractures of the larger population set.

[44] Both the northern and southern blunted terminations of West Candor (Figures 8 and 9, images A, B, C, D, and E) display relatively few orthogonal fractures. The largest population of orthogonal fractures in the southern blunted termination (Figures 8 and 9, image $\mathrm{C}$ ) displays two trends of $110^{\circ}-120^{\circ}$ (dominant) and $35^{\circ}-65^{\circ}$ (secondary). The orthogonal fractures in this area are fewer in number than those elsewhere in the region and are not as well developed, which reduces their visibility.

\subsection{En Echelon Fractures}

[45] En echelon fractures are most abundant below the southeast border scarp and within the eastern re-entrant where they display a strongly uniform orientation of $38^{\circ}$ (Figure 12, images $\mathrm{L}$ and $\mathrm{M}$ ). The sense of shear displayed 


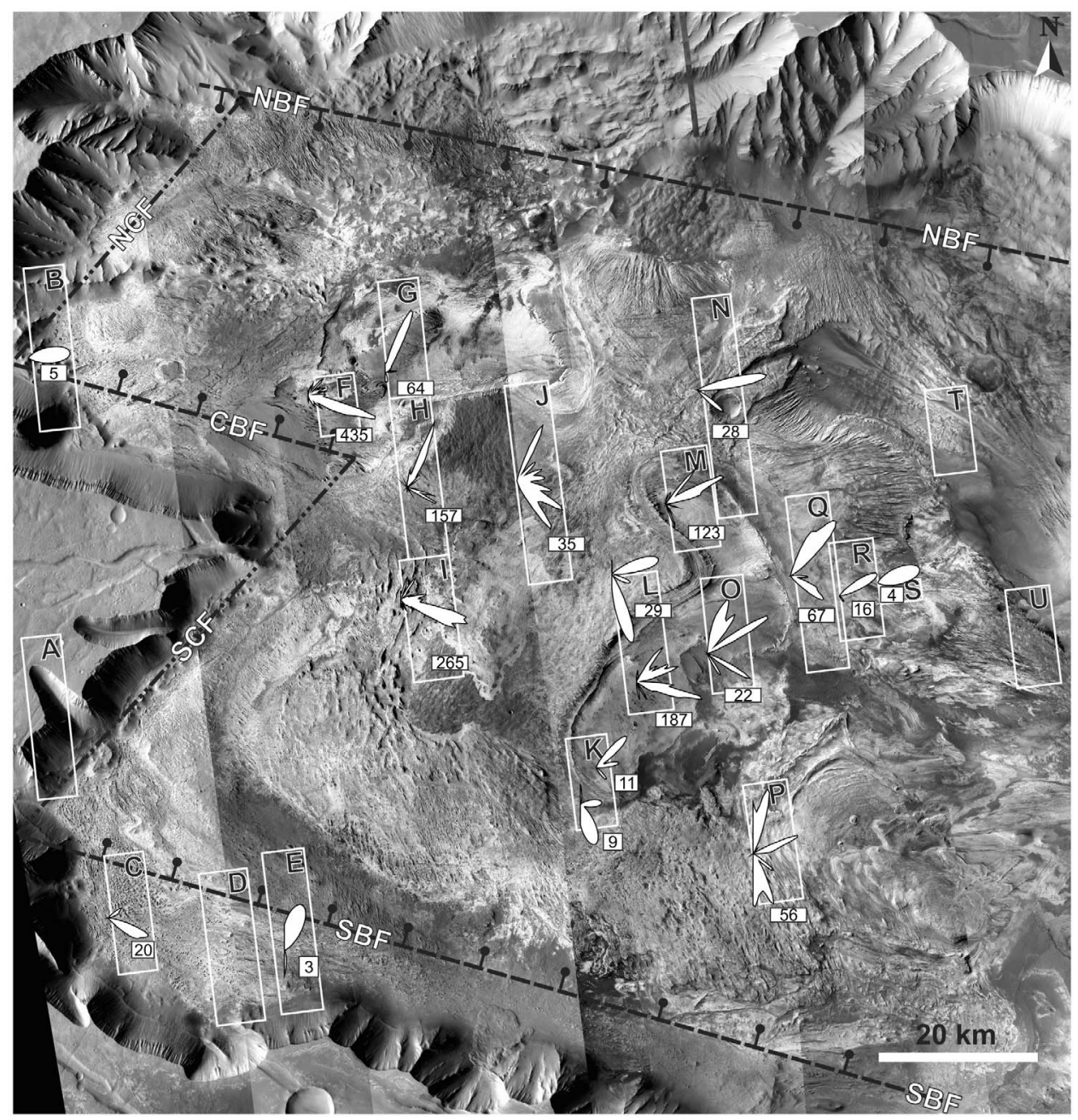

Figure 8. Histograms for the dominant orthogonal fracture orientations recorded in each HiRISE image location. The number of data points, $\mathrm{N}$, for each image is recorded to the bottom right of the histogram, and the size of each histogram has been scaled relative to the $\mathrm{N}$ value $(>20=$ large, $\mathrm{n} \leq 20=$ small).

by these en echelon fractures is not consistently left or right stepping but with the exception of the data from HiRISE images $\mathrm{E}$ and $\mathrm{H}$, the shear zone orientations are clustered according to their shear sense. En echelon arrays with a left stepping sense of shear have shear zone orientations from $11^{\circ}$ to $33^{\circ}$ while fracture arrays with a right stepping sense of shear have shear zone orientations from $40^{\circ}$ to $76^{\circ}$.

\subsection{Unidirectional Fractures}

[46] Along the northern border scarp of Ceti Mensa and to the north and west (Figure 13, images F and G), unidirectional fractures display a predominant trend of $60^{\circ}-105^{\circ}$ while the scarp itself is oriented $83^{\circ}$. These unidirectional fractures intersect at a $\sim 40^{\circ}$ angle creating angular outcrops aligned to the east (Figure 14), similar to the large unidirectional fractures along the southeast border scarp (Figure 11) but in greater abundance.

[47] In Figure 13 (image J), a strong peak of unidirectional fractures trends $105^{\circ}$ with a minor peak at $15^{\circ}$. Below these (Figure 13, image I), another large population displays two well defined trends of $\sim 70^{\circ}$ and $\sim 130^{\circ}$. Along the base of the southeast border scarp, the most prominent orientation is oblique to the scarp at $65^{\circ}-70^{\circ}$ (Figure 13, images L, O and Q) and is also reflected by one of two large unidirectional fracture sets that dissect the uppermost layers of the scarp (Figure 11). A second, less prominent trend of $\sim 40^{\circ}$ is parallel to the southeast border scarp (Figure 13, images $\mathrm{O}$ and $\mathrm{L}$ ).

[48] The northern blunted termination contains an abundance of unidirectional fractures with a strong trend of $97^{\circ}$. A lesser trend of $152^{\circ}$ is also present, parallel to the dominant fault trend in the area. At the southern blunted termination, within the slump material described by Okubo et al. [2008] and Okubo [2010], two prominent trends are present. The first trend from $55^{\circ}$ to $75^{\circ}$ is oblique to both the chasma forming faults but parallel to the abundant smallscale faults in the area. The second is from $110^{\circ}$ to $120^{\circ}$.

\subsection{Faults}

[49] The average apparent offset ranges between 5 and $15 \mathrm{~m}$ over a trace length of $100-350 \mathrm{~m}$, but occasionally faults of over a kilometer trace length are observed. Atop western Ceti Mensa (Figure 15, image H), faults with two general orientations occur. The larger population is oriented 


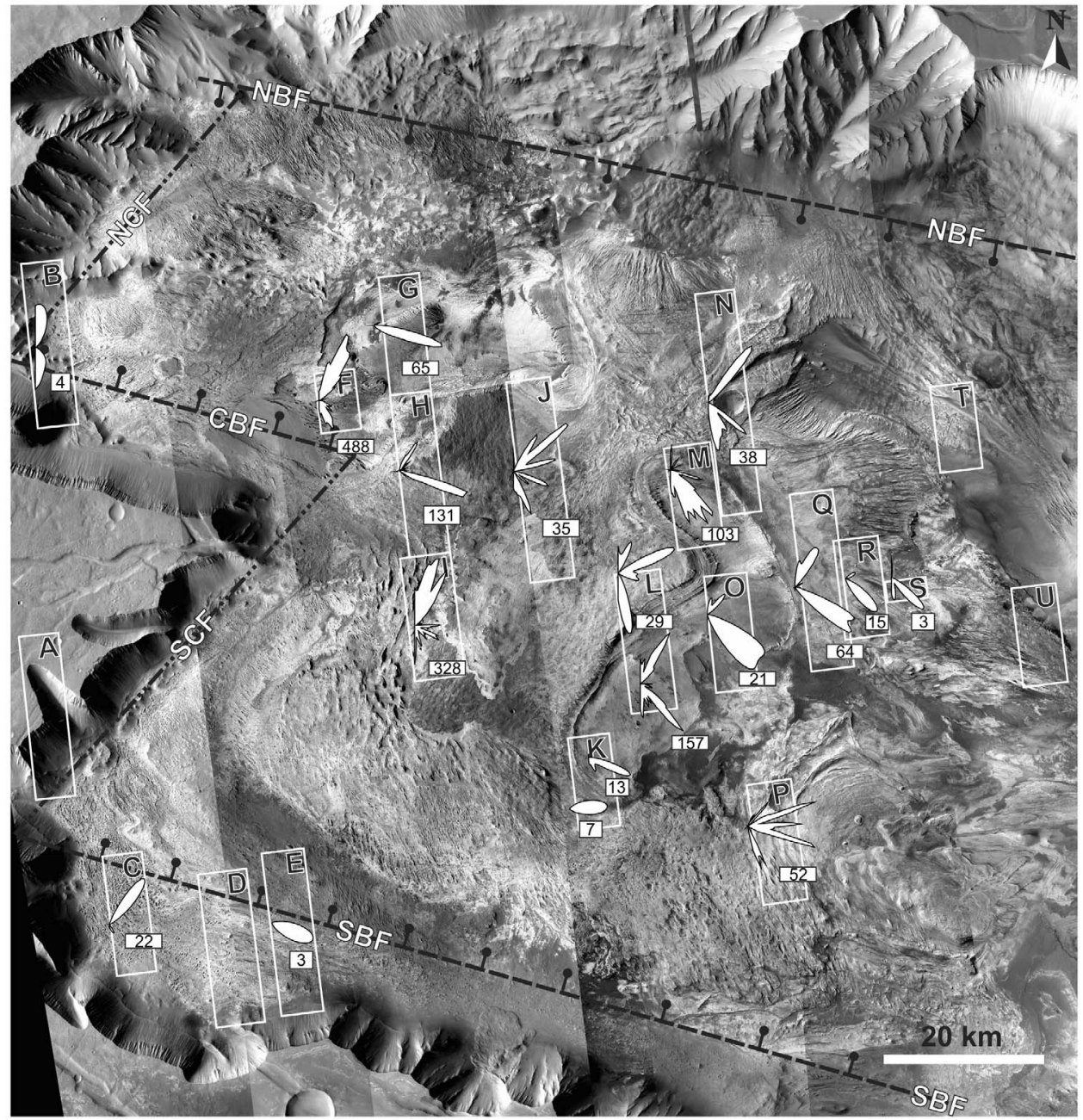

Figure 9. Histograms for the secondary orthogonal fracture orientations recorded in each HiRISE image location. The number of data points, $\mathrm{N}$, for each image is recorded to the bottom right of the histogram, and the size of each histogram has been scaled relative to the $\mathrm{N}$ value $(>20=$ large, $\leq 20=$ small).

from $135^{\circ}$ to $150^{\circ}$ and is composed of faults with lengths of less than $10 \mathrm{~m}$. The second fault peak of $72^{\circ}$ was predominantly recorded in the northern portion of Figure 15 (image $\mathrm{H})$, and these faults are generally longer than the faults to the south. Within the northern blunted termination, east of the NCF (i.e., in the hanging wall), 69 faults with orientations of $125^{\circ}-160^{\circ}$ were measured (Figure 15 , image B). The morphology of these faults is similar to the large population of faults observed atop western Ceti Mensa as they also have short lengths. Midway along the southeast border scarp (Figure 15, image $\mathrm{L}$ ) is a discrete, $4 \mathrm{~km}$ long scarp, parallel to the southeast border. Faults below the southeast border

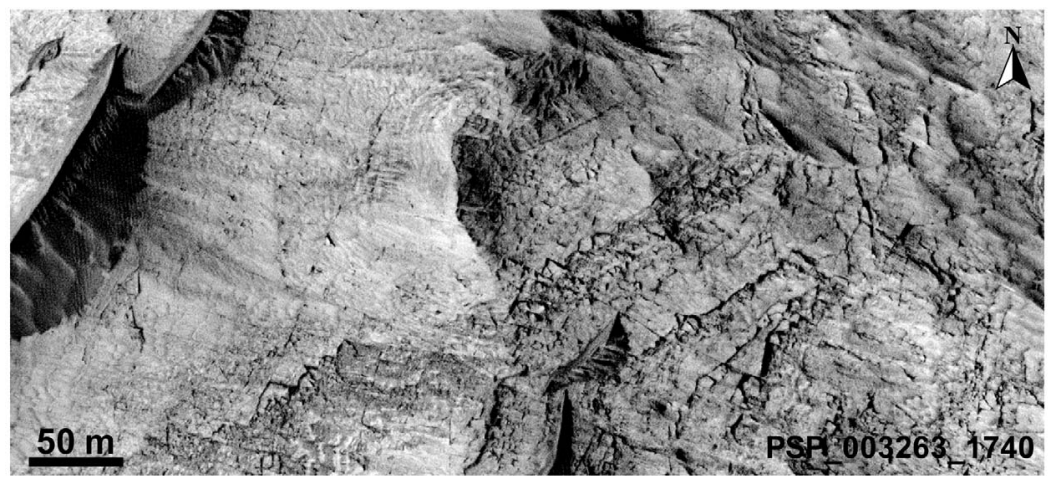

Figure 10. Orthogonal fractures are faintly visible below high albedo material and more clearly defined fractures not covered by later high albedo material. 


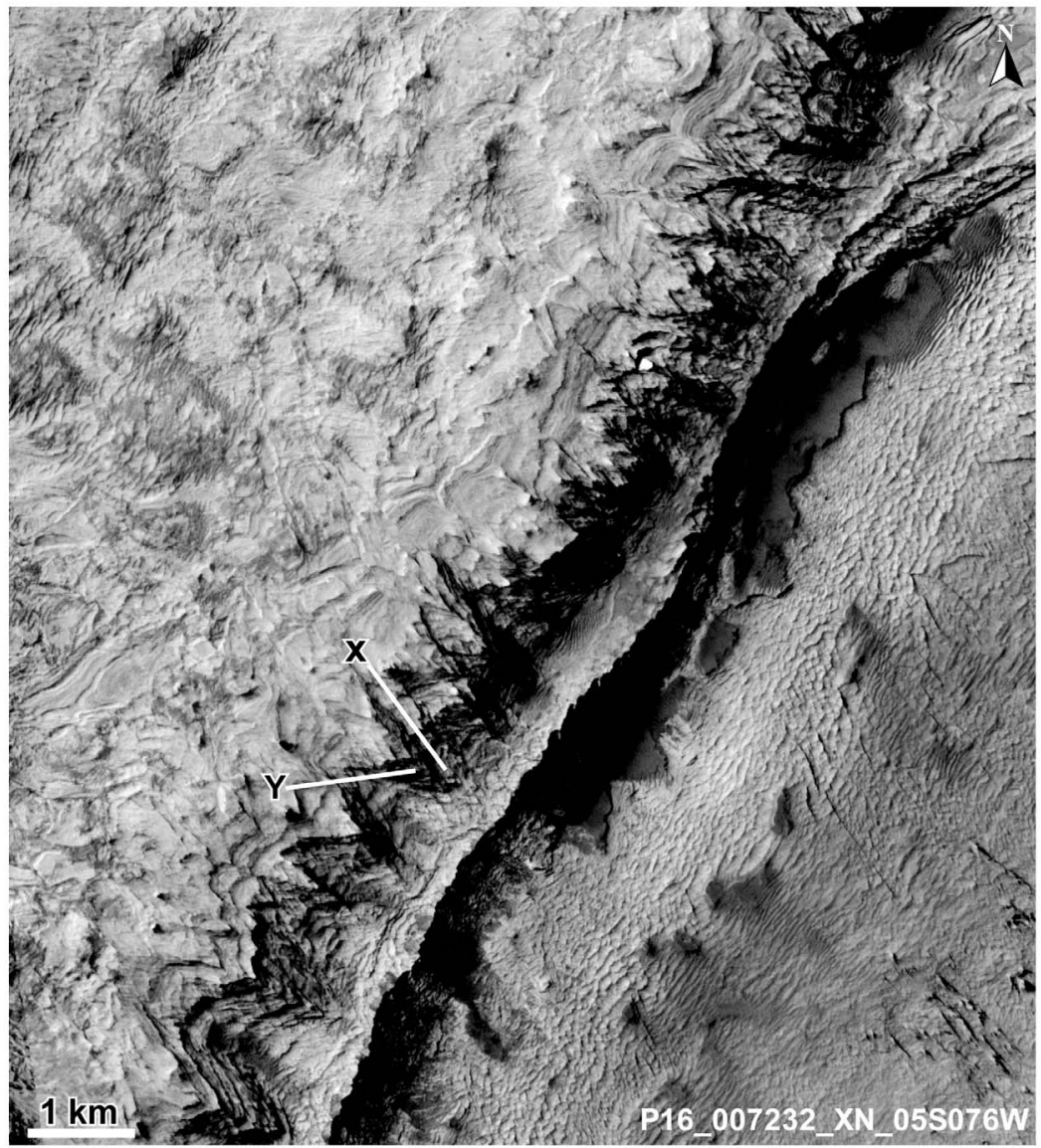

Figure 11. Large scale fractures along the southeast border scarp of Ceti Mensa dissecting only the uppermost layers of the section. The intersection of two fracture orientations parallel to $\mathrm{X}$ and $\mathrm{Y}$ forms the angular outcrops pointing east. (P16_007232_XN_05S076W (5.44 m/pixel)).

scarp are perpendicular to the discrete scarp and also have short lengths.

[50] Approximately $65 \%$ of all faults recorded are located within the highly deformed material documented by Okubo et al. [2008] and Okubo [2010]. These faults have a consistent strike of $\sim 70^{\circ}$ (Figure 15, images C, D, and E), similar to the trend of normal faults reported by Okubo et al. [2008].

\subsection{Curved Fractures}

[51] To the north and east of Ceti Mensa's eastern prominence (Figure 16, images N and Q), populations of curved fractures with well-defined orientations parallel to the border faults are observed (Figure 16). Below the southeast border scarp (Figure 16, image L), a large $75^{\circ}$ trend is present parallel to several large unidirectional fractures and the $\mathrm{Y}$ orientation of the large scale fractures in Figure 11. Figure 16 (image T) contains the largest population of curved fractures that display a well defined $15^{\circ}-28^{\circ}$ trend.

\section{Discussion}

\subsection{Regional Trends}

[52] The ILDs of West Candor have clearly been subjected to deformation in which the resulting small-scale structures developed non-random trends. Data presented in Table 2 indicates that there is no obvious relationship between the orientation of dominant fractures and local slope. The consistent orientation and wide distribution throughout West Candor Chasma suggest regional control, rather than the localized effects of topography. There also appears to be no clear relationship between fracture orientation and elevation. Dominant fracture orientations (Figure 6; A), suggest two clusters of $120^{\circ}$ fracture orientation at $\sim 1600 \mathrm{~m}$ and $\sim 3000 \mathrm{~m}$. However, this apparent relationship is most likely a sampling bias for these elevations, as result of the large number of data collected in HiRISE images F, $\mathrm{H}$ and I. The bias for these elevations is also evident in the $40^{\circ}$ clusters within the secondary fractures versus elevation graph (Figure 6, image B). The graphs for unidirectional and curved fractures (Figure 6, images $\mathrm{C}$ and $\mathrm{D}$ ) also present a sampling bias at $3000 \mathrm{~m}$ elevation. Sampling biases are also present for $1000 \mathrm{~m}$ and $3000 \mathrm{~m}$ in the graph of fault orientations versus elevations (Figure 6, image E) for a large range of orientations. The small sample size for the en echelon fractures (Figure 6, image F) does not provide enough data to draw any definitive conclusions about their genesis. No data set shows clear isolated clusters of the same orientation at different elevations. In the larger data sets, the full range of orientations is present at all elevations with sufficient data. Hence we suggest that the fractures are present throughout the entire 


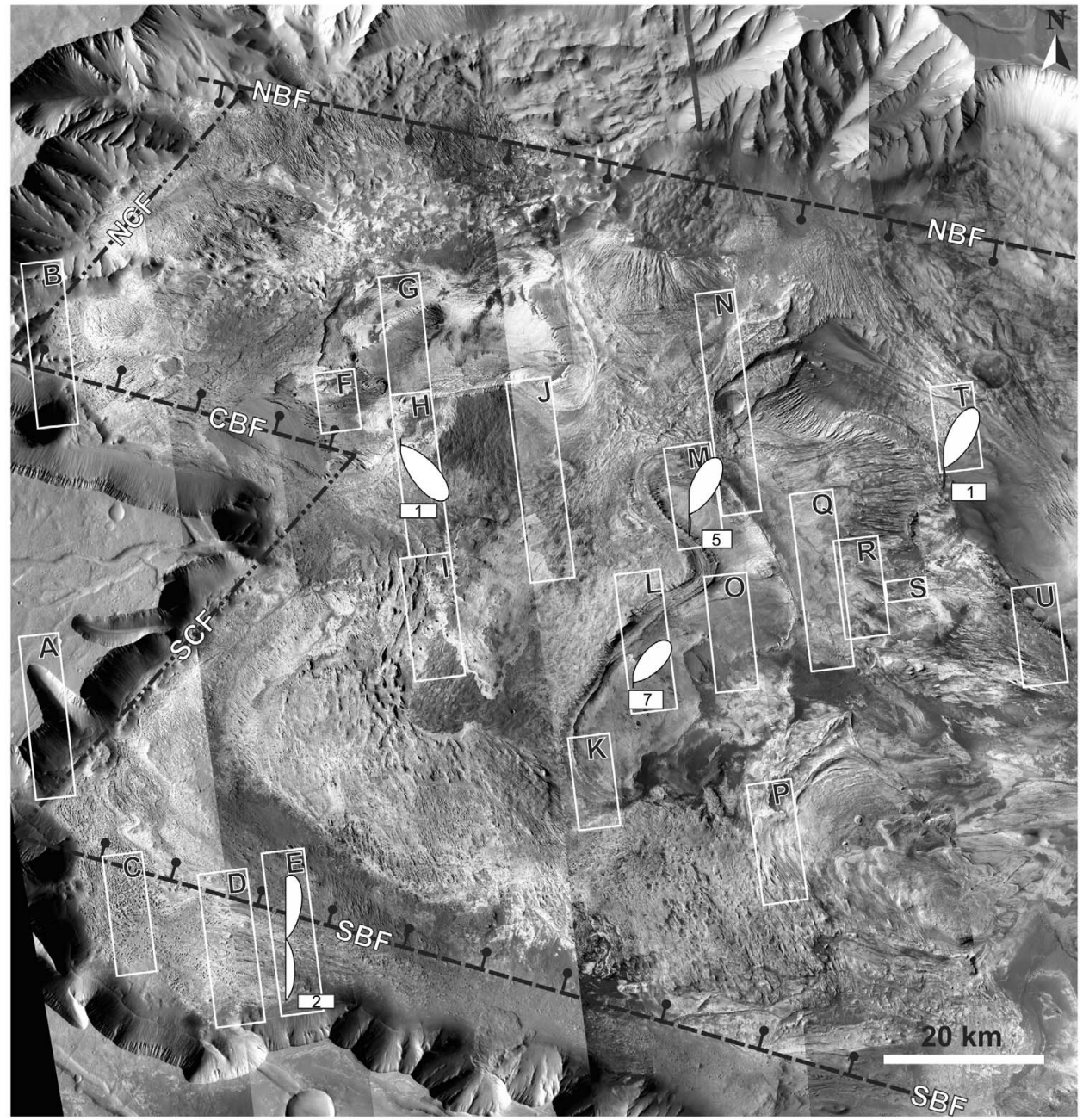

Figure 12. Histograms for the en echelon fracture orientations recorded in each HiRISE image location. Because of the small number of data points, the size of each histogram has not been scaled relative to the $\mathrm{N}$ value.

ILD stratigraphy and not governed by particular stratigraphic units.

[53] Within the ILD of West Candor, several regional trends were recognized in the orientations of deformational features and interpretations of their genesis are given. The most prominent trend is found within the unidirectional fractures and orthogonal fracture sets, reflecting the postulated orientations of the border $\left(101^{\circ}-107^{\circ}\right)$ and cross $\left(40^{\circ}\right)$ faults. The second most prominent trend is $70^{\circ}$ and was displayed by faults, unidirectional fractures and orthogonal fractures. A third trend is observed within the faults of West Candor, oriented $135^{\circ}-150^{\circ}$, roughly perpendicular to the inferred cross fault orientations. Assuming the simplest scenario of ILD deformation, a continuation of the imposed stress field which initially produced the chasma-forming faults, with a similar orientation, would produce small-scale deformational features and corresponding orientations. The number and distribution of deformational features may have been influenced by heterogeneities within the ILD (e.g., bed thickness, particle size, competency, etc.) and could account for their inhomogeneous distribution throughout the study area.
[54] During a continuation of the imposed stress field, unidirectional and dominant orthogonal fracture sets formed in direct response to the imposed stresses, parallel to the maximum horizontal compressive stress. Where a mutually crosscutting relationship is present, both orthogonal fracture orientations (dominant and secondary) may be directly linked to the stresses which acted to produce the blunted terminations of West Candor. However, where no crosscutting relationship is present, the alignment of the stresses producing the secondary fracture sets is more ambiguous and may have resulted directly from the imposed stress or indirectly by visco-elastic relaxation or warping [Rives et al., 1994].

[55] Along Ceti Mensa's southeast border scarp, orthogonal and unidirectional fracture histograms display several consistent trends parallel to the chasma-forming faults and the $70^{\circ}$ trend which is discussed later. The alignment of orthogonal (Figures 8 and 9, images $\mathrm{K}, \mathrm{L}$ below, O, Q, R, and $\mathrm{M}$ ) and unidirectional fractures (Figure 13, images L, O, $\mathrm{R}$, and $\mathrm{M}$ ) parallel to the southeast border scarp may indicate that a large fault underlies the southeast border scarp. The interaction of the imposed regional stress and an underlying 


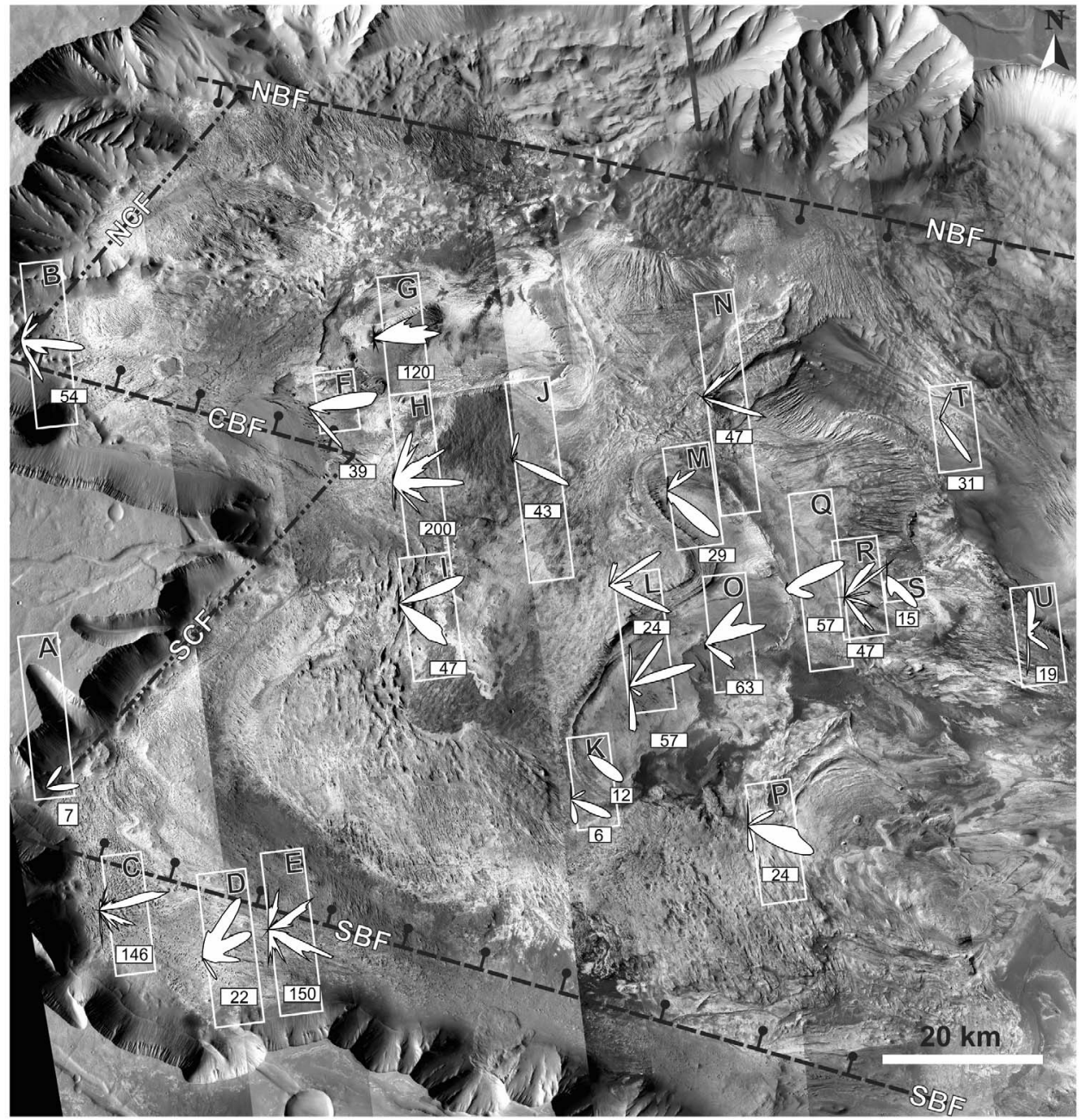

Figure 13. Histograms for the unidirectional fracture orientations recorded in each HiRISE image location. The number of data points, $\mathrm{N}$, for each image is recorded to the bottom right of the histogram, and the size of each histogram has been scaled relative to the $\mathrm{N}$ value $(>20=$ large, $\leq 20=$ small).

fault could generate the observed fracture orientations along the southeast border scarp. This proposed fault may be another preexisting blind thrust (below a wrinkle ridge) aligned concentrically about the Tharsis region that was exploited later to form Ceti Mensa's southeast border scarp.
The distance from the southeast border scarp to the SCF is $42 \mathrm{~km}$, roughly the same distance between the NCF to the SCF. The frequency distribution of wrinkle ridge spacing reported by Watters [1991] based on 2934 measurements displays an average spacing of $30 \mathrm{~km}$ (the mode, instead of

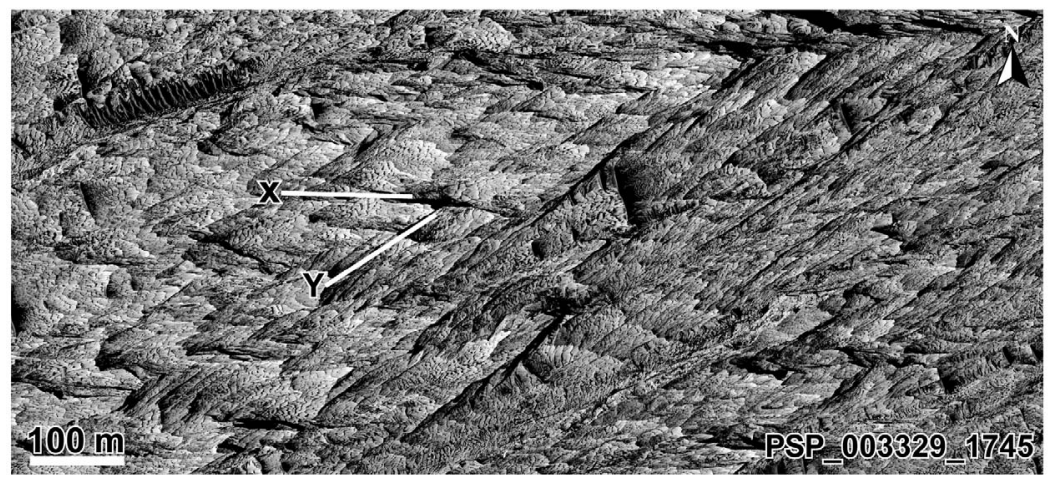

Figure 14. East pointing angular outcrops to the north of Ceti Mensa's northern border scarp formed by the intersection of two unidirectional fracture sets parallel to X and Y (HiRISE image G). 


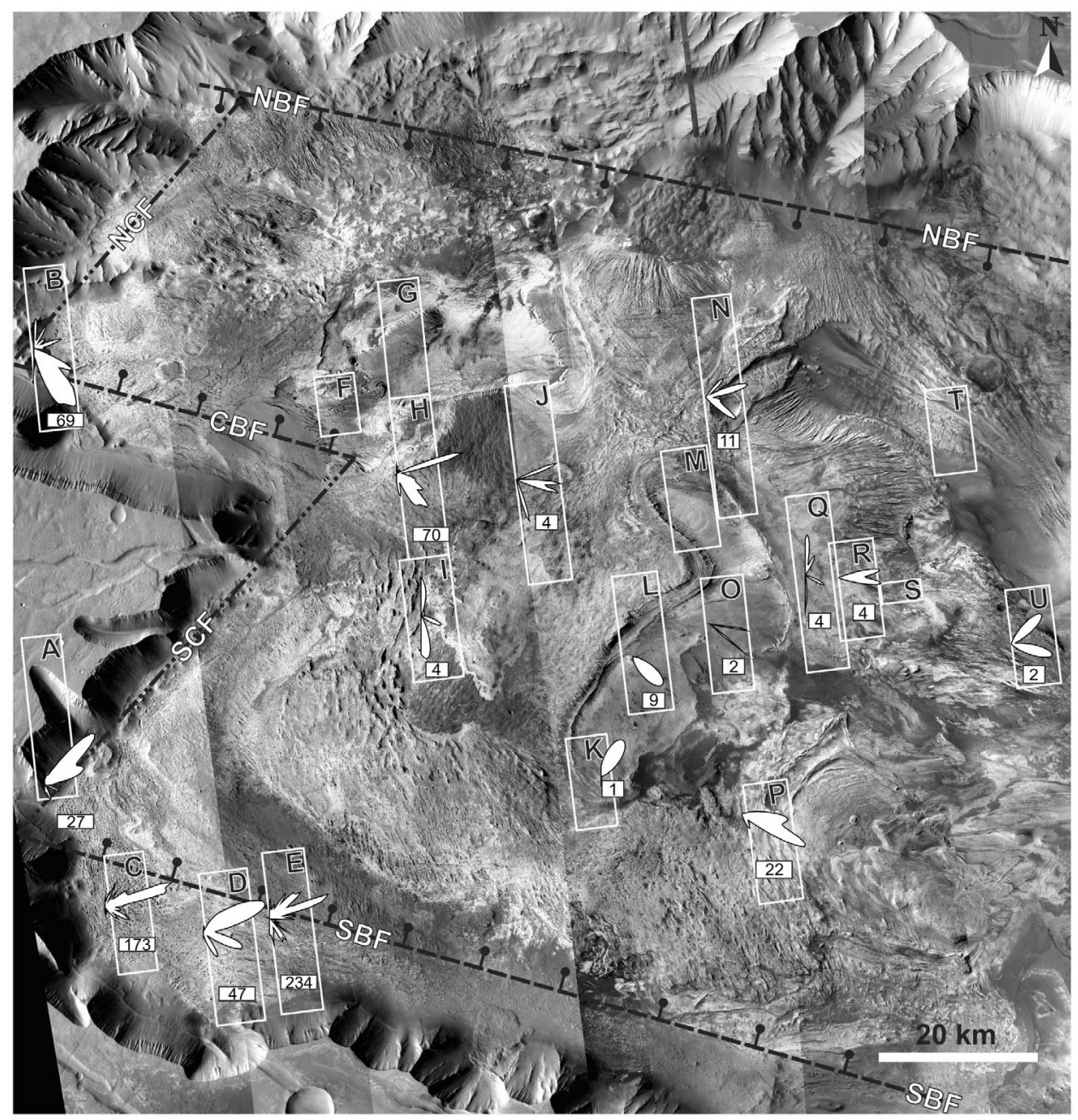

Figure 15. Histograms for the trends of fault traces recorded in each HiRISE image location. The number of data points, $\mathrm{N}$, for each image is recorded to the bottom right of the histogram, and the size of each histogram has been scaled relative to the $\mathrm{N}$ value $(>20=$ large, $\leq 20=$ small $)$.

the mean was used to obtain the most reliable measure because of the strongly skewed distribution). The value of $\sim 42 \mathrm{~km}$ between cross-faults and between the SCF and southeast border scarp is well within the skewed frequency distribution range of ridge spacing. Hence we suggest that a buried basement fault is located beneath the southeast border scarp of Ceti Mensa and that the visible scarp is the erosional surface feature of that fault within the ILD. The fault may have been active during basin formation.

[56] The prominent $133-151^{\circ}$ trend of the small-scale faults in areas B and $\mathrm{H}$ of Figure 15 is slightly more than $90^{\circ}$ from the inferred orientation of the nearby cross fault. In both locations, relatively large populations of short faults with very uniform orientations are present at the intersection of a border and cross fault. Assuming normal displacement, these highly uniform faults of short length are consistent with small cross faults termed "release faults" by Destro et al. [1990]. The faults perpendicular to the southeast border scarp identified in area L of Figure 15 may also be release faults that accommodated bending stresses from displacement along the large underlying cross fault proposed above.
[57] Release faults are cross faults that form to alleviate bending stresses accumulated by differential vertical displacement in the hanging wall of a normal fault (Figure 17) and die out before intersecting another normal fault [Destro, 1995]. Release faults form near the fault tip and do not cut normal fault planes or detachment surfaces [Destro, 1995]. Generally, only one or two major release faults form over strike ramps or at the margins of a normal fault but smaller release faults may occupy intermediate positions. If a major release fault does not form, numerous small release faults may form along the length of the normal fault to accommodate the bending stresses [Destro, 1995].

[58] The $70^{\circ}$ trend displayed by faults, unidirectional fractures and orthogonal fractures (Figures 13 and 15, images C, D, E, H, I, J, L, N, O, and Q) is most abundant in the southwest of the study area (Figures 13 and 15, images C, D, and E). The material in which they form is described by Okubo et al. [2008] and Okubo [2010] as slump material shed off the southern flank of Ceti Mensa and eroded by aeolian processes. However, the $70^{\circ}$ trend displayed by faults and unidirectional fractures is also present in the other parts of the study area outside the area covered by the 


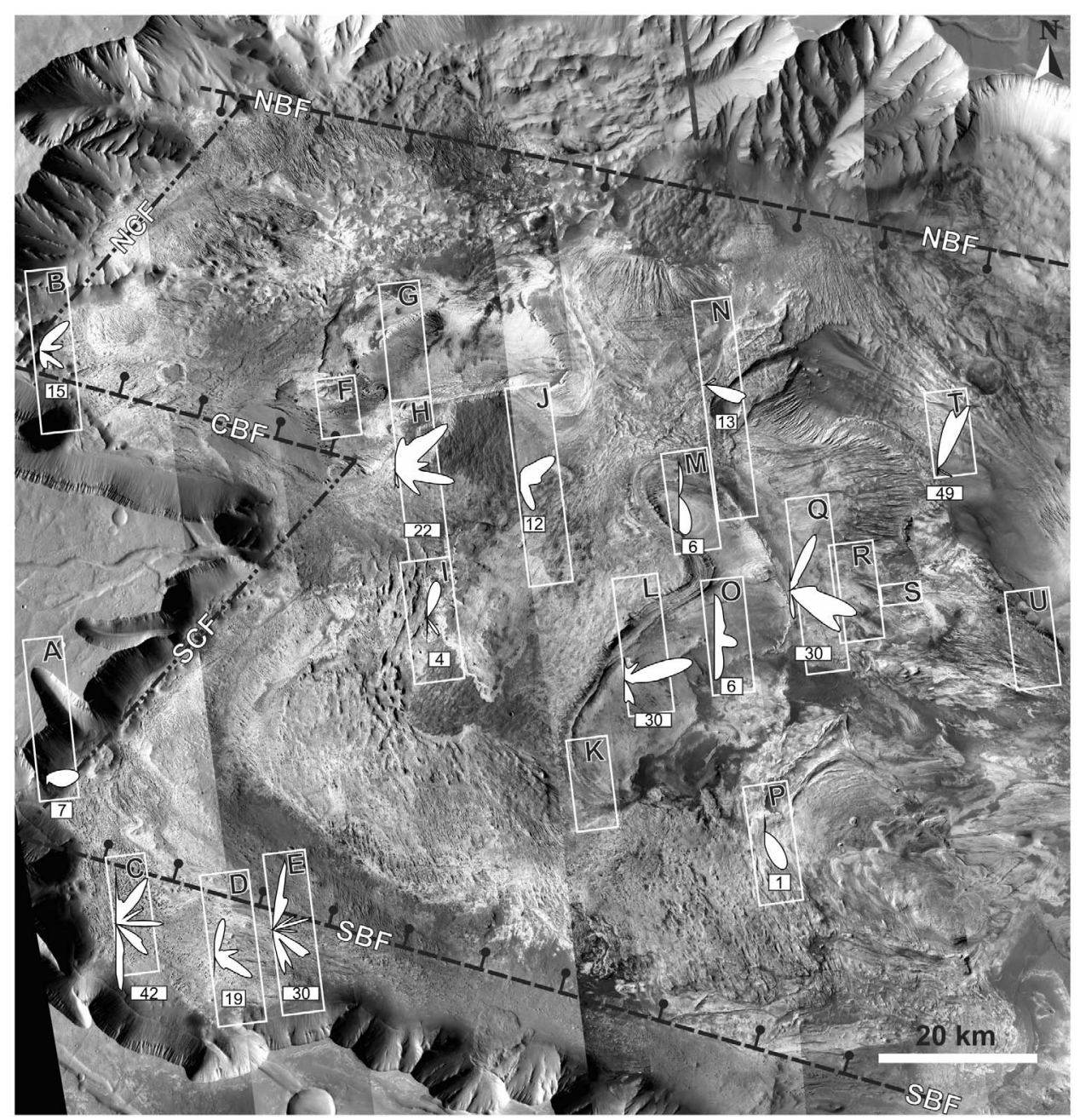

Figure 16. Histograms for the curved fracture orientations recorded in each HiRISE image location. The number of data points, $\mathrm{N}$, for each image is recorded to the bottom right of the histogram, and the size of each histogram has been scaled relative to the $\mathrm{N}$ value $(>20=$ large, $\leq 20=$ small).

slumped material. The $70^{\circ}$ trend is prominent in faults atop northwestern Ceti Mensa, through central Ceti Mensa and north of the northern re-entrant. In these areas, the fault trend is almost parallel to the northern border scarp and is therefore more likely to have resulted from the same deformation event and not from slumping. This connection may suggest that none of the deformational features with a $70^{\circ}$ orientation resulted from a slumping event but that it records a significant trend of a regional scale. It does however not appear to correlate with the regional trends within West Candor, nor is it reflected by any obvious trends of faults within the chasm walls of Candor, which record the orientation of faulting during the initial collapse. Hence one possibility is that these features result from a regional stress that post-dates the collapse of the chasm. However, recent modeling of stresses during the formation of Valles Marineris by Andrews-Hanna [2012b, Figure 4e] suggests a broad band of high tensile stresses oriented approximately SW-NE in the area of Candor and Ophir chasma. The predicted tensile failure orientation in this band would be approximately $70^{\circ}$. If the features observed here can be attributed to the stress orientation predicted by this model, they would correspond to

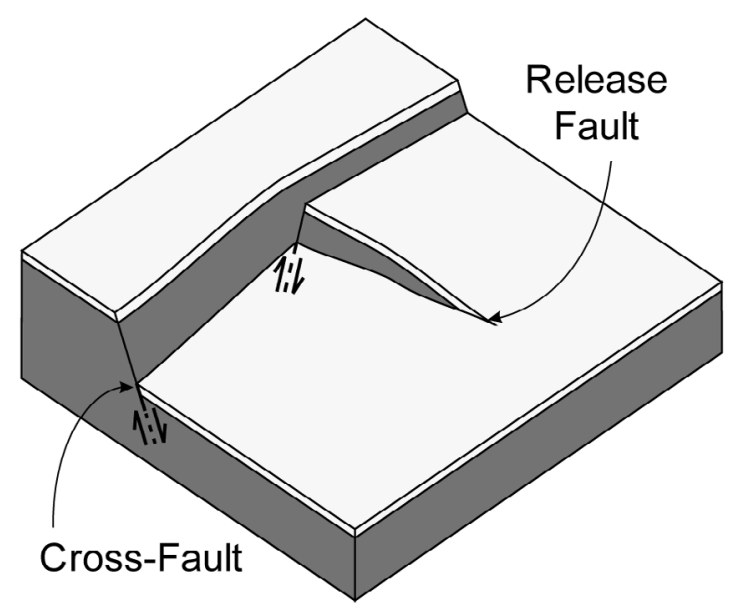

Figure 17. Block diagram of a release fault (modified from Destro [1995]). Release faults accommodate predominantly vertical/dip-slip displacement and die out within the hanging wall before connecting to a second normal fault [Destro, 1995]. 


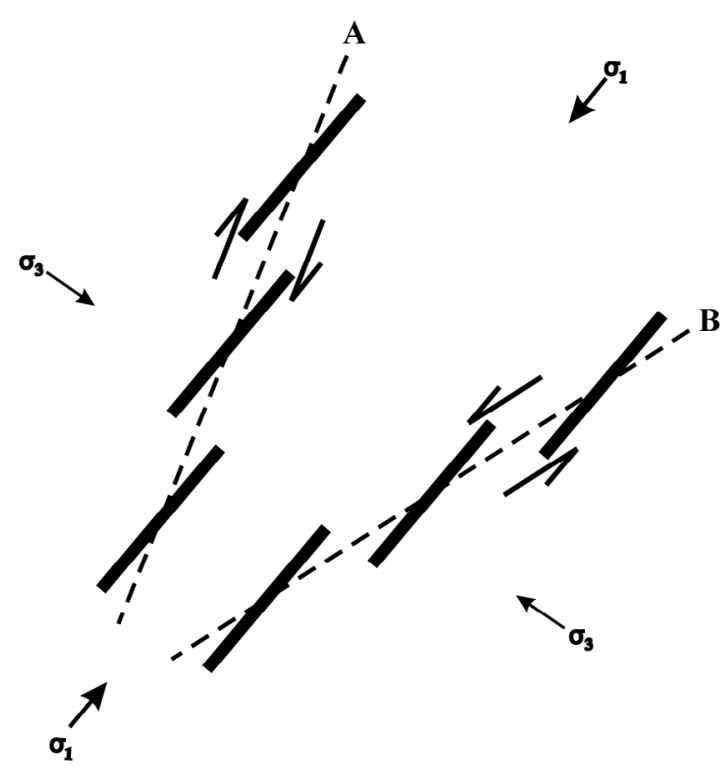

Figure 18. Diagram for the formation of the conjugate en echelon arrays clustered about two shear zone orientations and a common maximum compressive stress orientation. Dashed line labeled A shows the average orientation $\left(22^{\circ}\right)$ of the sinistrally offset en echelon fractures, produced by a dextral shear sense. Dashed line labeled B shows the average orientation $\left(58^{\circ}\right)$ of the dextrally offset en echelon fractures, produced by a sinistral shear sense. The orientation of the individual fractures that compose the en echelon arrays is $40^{\circ}$, parallel to the maximum compressive stress (modified from Twiss and Moores [2007]).

stresses related to Valles Marineris formation. Outside West Candor, the $70^{\circ}$ orientation appears in several features, such as a graben complex south of Echus Chasma $\left(78^{\circ}-84^{\circ}\right)$, the southern border of Juventae Chasma $\left(83^{\circ}\right)$ and a pit chain that intersects the SW border of Hebes Chasma $\left(74^{\circ}\right)$. All of these regions are within Andrews-Hanna's band of NW-SE-oriented tensile stress.

[59] The locations of the left and right stepping en echelon fracture sets are in close proximity and of similar orientation to the southeast border scarp and the proposed fault along it. While the number of fracture sets is limited, the two clusters of shear orientations could be interpreted as a conjugate set with a common maximum compressive stress direction of $\sim 40^{\circ}$ (Figure 18). This orientation for the maximum compressive stress is consistent with one of the primary orthogonal fractures orientations.

[60] Curved fractures display broad, multimodal orientation trends, only weakly subparallel to the border and cross faults. Hence, their origin cannot directly be linked to the movement of chasma-forming faults or to any other processes.

[61] Other than the curved fractures, all of the trends discussed above indicate their development is the result of a pervasive underlying mechanism and not local topography or material properties.

\subsection{Timing and Significance of Small-Scale Deformational Features}

[62] The occurrence of small-scale deformational features within ILD implies ILD had already formed and lithified before deformation. For the purpose of further discussion, we accept the prevalent view that ILD formed as ancestral basin fill [Lucchitta, 1990, 1999; Witbeck et al., 1991; Lucchitta et al., 1994; Schultz, 1998; Chapman and Tanaka, 2001; Fueten et al., 2006, 2008; Okubo et al., 2008; Okubo, 2010]. The orientations of the deformational features within the ILD of West Candor record three strong trends, one of $70^{\circ}$ and two that are parallel to the chasma-forming faults, suggesting the study area has undergone two distinct periods of deformation. The small displacement of the exposed deformational features indicates that they record minor amounts of strain (consistent with the new modeling results of Andrews-Hanna [2012a, 2012b]. Deformational features can form in response to applied stresses without the need for reactivation of major faults. However, the model of Wilkins and Schultz [2003] requires slip on the border faults to produce slip on cross faults. Slip on the cross faults may be the origin of the nearby cross-fault-parallel fractures. This would imply that that some slip on the border faults is required to produce cross-fault - parallel fractures. This slip may be at depth resulting in minor surface strain. Along the southern blunted termination, within the material described by Okubo et al. [2008] as an eroded slump, the small number of orthogonal fractures oriented parallel to the border and cross faults appears to represent a period of deformation that post-dates the eroded slump. Fractures which formed before the onset of slumping would have been obliterated during transport or modified to display highly variable orientations. The small number, immature nature and orientations of these fractures are consistent with fractures formed recently in response to stresses parallel to the border and cross faults.

[63] The $70^{\circ}$ fractures and faults are enigmatic. It is possible that they were formed by a local band of tensile stress that crossed the main extension structure at the same time, as suggested by the model of Andrews-Hanna [2012b]. A key result of his modeling is the apparent complexity of the local stress orientation during a seemingly simple process of regional extension. It is also possible that this set of fractures and faults formed by an unknown later event.

\section{Conclusions}

[64] The small-scale faults and fractures within the ILD of West Candor Chasma record the orientations of stress regimes acting on the region. By categorizing the small-scale deformational features by morphology and measuring their orientations, the imposed stresses are revealed, providing a better understanding of the geologic history of the ILD and Candor Chasma.

[65] Within the measured orientations for all but the curved fractures, strong and well-defined orientation preferences are visible indicating non-random alignments controlled by consistent and pervasive underlying mechanisms. The alignment of these preferred orientations parallel to the chasma-forming faults indicates a close relationship between them. The orientations of small-scale deformational features suggests they likely produced by a continuation of the imposed stress which initially produced the chasma forming faults and hence the basins. This relationship implies that the stress field was active after ILD lithification.

[66] The relationship observed between the orientations of small-scale surface structures and the imposed stress field 
suggests that a large fault underlies the southeast border scarp, possibly another preexisting blind thrust.

[67] The recurrence of $\mathrm{a} \sim 70^{\circ}$ trend, parallel to the northern border scarp, within the orientations of orthogonal and unidirectional fractures as well as numerous faults, may be the consequence of the regional variation of tensile stresses during chasma formation or may indicate another period of deformation that may not have been limited to Candor Chasma.

[68] The data presented in this paper demonstrates that small-scale deformational features can display regionally consistent orientations and offer insights into the regional stresses. Thus, such features provide one of the few tools available for exploring and documenting the post-lithification stress history of deposits on Mars. Measuring the fracture orientation patterns throughout the planet in deposits of different ages will provide a valuable database for establishing the evolution of stresses on the planet and give a baseline of data to test tectonic models. One application may be to study the orientation of fractures within impact craters that contain layered deposits such as Becquerel and Gale. The absence or presence of, for example, axisymmetrical patterns within fractures of layered deposits could provide information on the post-lithification history of deposits within those craters or on the role of the central uplift. Hence, fracture orientation can provide important insights into the geological history of layered deposits, similar to the way that the nature of faulting can provide insights into the physical properties of the host rock [Okubo, 2012].

[69] Acknowledgments. We thank the HRSC experiment teams at DLR Berlin and Freie Universitaet Berlin and the Mars Express project teams at ESTEC and ESOC for their successful planning and acquisition of data as well as for making the processed data available to the HRSC team. We also want to thank the CTX, HiRISE, and CRISM teams for making their data available. This project was partially funded by an NSERC discovery grant to F. Fueten. Pangaea Scientific thanks P. Budkewitsch and Canada Centre for Remote Sensing for support of ORION under contract NRCan-01-0102 E. H. was partly funded by the Helmholtz Alliance "Planetary Evolution and Life." We are grateful to C. Okubo and an anonymous reviewer for thorough reviews and detailed comments. We thank M. Lozon for preparing the illustrations. We also thank the International Space Science Institute for their support by providing the authors with an opportunity to discuss the topic, and we thank the team members for their collaboration.

\section{References}

Andrews-Hanna, J. C. (2012a), The formation of Valles Marineris: 1 Tectonic architecture and the relative roles of extension and subsidence, J. Geophys. Res., 117, E03006, doi:10.1029/2011JE003953.

Andrews-Hanna, J. C. (2012b), The formation of Valles Marineris: 2. Stress focusing along the buried dichotomy boundary, J. Geophys. Res., 117, E04009, doi:10.1029/2011JE003954.

Bai, T., L. Maerten, M. R. Gross, and A. Aydin (2002), Orthogonal cross joints: Do they imply a regional stress rotation? J. Struct. Geol., 24, 77-88, doi:10.1016/S0191-8141(01)00050-5.

Banerdt, W. B., R. J. Phillips, N. H. Sleep, and R. S. Saunders (1982), Thick shell tectonics on one-plate planets: Applications to Mars, J. Geophys. Res., 87, 9723-9733, doi:10.1029/JB087iB12p09723.

Banerdt, W. B., M. P. Golombek, and K. L. Tanaka (1992), Stress and tectonics on Mars, in Mars, edited by H. H. Kieffer et al., pp. 249-297, Univ. of Arizona Press, Tucson, Arizona.

Beyer, R. A., and A. S. McEwen (2005), Constraints on the origin of fine layers in Ganges Mensa and Hebes Mensa, Mars, Proc. Lunar Planet. Sci. Conf., 31st, Abstract 1070.

Blasius, K. R., J. A. Cutts, J. E. Guest, and H. Masursky (1977), Geology of the Valles Marineris; first analysis of imaging from the Viking 1 orbiter primary mission, J. Geophys. Res., 82, 4067-4091, doi:10.1029/ JS082i028p04067.

Caputo, R. (1995), Evolution of orthogonal sets of coeval extension joints, Terra Nova, 7, 479-490, doi:10.1111/j.1365-3121.1995.tb00549.x.
Catling, D. C., S. E. Wood, C. Leovy, D. R. Montgomery, H. M. Greenberg, C. R. Glein, and J. M. Moore (2006), Light-toned layered deposits in Juventae Chasma, Mars, Icarus, 181, 26-51, doi:10.1016/j.icarus.2005. 10.020 .

Chapman, M. G. (2002), Layered, massive, and thin sediments on Mars: Possible Late Noachian to Late Amazonian tephra?, in Volcano-Ice Interactions on Earth and Mars, edited by J. L. Smellie and M. G. Chapman, pp. 273-293, Geol. Soc. Spec. Publ., London, doi:10.1144/GSL. SP.2002.202.01.14.

Chapman, M. G., and K. L. Tanaka (2001), Interior trough deposits on Mars: Subice volcanoes?, J. Geophys. Res., 106(E5), 10,087-10,100, doi:10.1029/2000JE001303.

Clarke, J. D. A., and M. C. Bourke (2009), Recognition criteria of spring deposits on Mars at all scales: Evidence from the Dalhousie Springs analog (Australia), Proc. Lunar Planet. Sci. Conf., 40th, Abstract 1102.

Destro, N. (1995), Release fault: A variety of cross fault in linked extensional fault systems in the Sergipe-Alagoas Basin, NE Brazil, J. Struct. Geol., 17, 615-629, doi:10.1016/0191-8141(94)00088-H.

Destro, N., L. S. Chagas, D. S. N. Chiossi, E. C. V. Machado, and G. H. N. Masiero (1990), Sistema em 'relay' associado a regime extensional na borda oeste da Bacia de Sergipe-Alagoas, XXXVI Congresso Brasileiro de Geologia Natal, Anais, 5, 2226-2237.

Dohm, J. M., and K. L. Tanaka (1999), Geology of the Thaumasia region, Mars: Plateau development, valley origins, and magmatic evolution, Planet. Space Sci., 47, 411-431, doi:10.1016/S0032-0633(98)00141-X. Engelder, T., and P. Geiser (1980), On the use of regional joint sets as trajectories of paleostress fields during the development of the Appalachian plateau, N.Y, J. Geophys. Res., 85, 6319-6341, doi:10.1029/ JB085iB11p06319.

Fueten, F., R. Stesky, P. MacKinnon, E. Hauber, K. Gwinner, F. Scholten, T. Zegers, and G. Neukum (2006), A structural study of an interior layered deposit in southwestern Candor Chasma, Valles Marineris, Mars, using high resolution stereo camera data from Mars Express, Geophys. Res. Lett., 33, L07202, doi:10.1029/2005GL025035.

Fueten, F., et al. (2007), Faulting of ILD deposits on Ceti Mensa, western Candor Chasma, Mars, Proc. Lunar Planet. Sci. Conf., 38th, Abstract 1388.

Fueten, F., R. Stesky, P. MacKinnon, E. Hauber, T. Zegers, K. Gwinner, F. Scholten, and G. Neukum (2008), Stratigraphy and structure of interior layered deposits in west Candor Chasma, Mars, from High Resolution Stereo Camera (HRSC) stereo imagery and derived elevations, J. Geophys. Res., 113, E10008, doi:10.1029/2007JE003053.

Fueten, F., H. Racher, R. Stesky, P. MacKinnon, E. Hauber, P. C. McGuire, T. Zegers, and K. Gwinner (2010), Structural analysis of interior layered deposits in northern Coprates Chasma, Mars, Earth Planet. Sci. Lett., 294, 343-356, doi:10.1016/j.eps1.2009.11.004.

Gaddis, L. R., J. Skinner, T. Hare, R. Kirk, T. Titus, L. Weller, and G. Neukum (2006), Morphology and morphometry of Ceti Mensa, West Candor Chasma, Mars, Proc. Lunar Planet. Sci. Conf., 37th, Abstract 2076.

Golombek, M. P., and R. J. Phillips (2010), Mars tectonics, in Planetary Tectonics, edited by T. R. Watters and R. A. Schultz, pp. 183-233, Cambridge Univ. Press, Cambridge, U. K

Hynek, B. M., R. J. Phillips, and R. E. Arvidson (2003), Explosive volcanism in the Tharsis region: Global evidence in the Martian record, J. Geophys. Res., 108(E9), 5111, doi:10.1029/2003JE002062.

Jaumann, R., et al. (2007), The high-resolution stereo camera (HRSC) experiment on Mars Express: Instrument aspects and experiment conduct from interplanetary cruise through the nominal mission, Planet. Space Sci., 55, 928-952, doi:10.1016/j.pss.2006.12.003.

Komatsu, G., G. G. Ori, P. Ciarcelluti, and Y. D. Litasov (2004), Interior layered deposits of Valles Marineris, Mars: Analogous subice volcanism related to Baikal Rifting, Southern Siberia, Planet. Space Sci., 52, 167-187, doi:10.1016/j.pss.2003.08.003.

Lewis, K., O. Aharonson, J. Grotzinger, R. Kirk, A. McEwen, and T.-A. Suer (2008), Quasi-periodic bedding in the sedimentary rock record of Mars, Science, 322, 1532-1535, doi:10.1126/science.1161870.

Lorenz, J. C., J. L. Sterling, D. S. Schechter, C. L. Whigham, and J. L. Jensen (2002), Natural fractures in the Spraberry formation, Midland Basin, Texas: The effects of mechanical stratigraphy on fracture variability and reservoir behavior, AAPG Bull., 86, 505-524.

Lucchitta, B. K. (1979), Landslides in Valles Marineris, Mars, J. Geophys. Res., 84, 8097-8113, doi:10.1029/JB084iB14p08097.

Lucchitta, B. K. (1987), Recent mafic volcanism on Mars, Science, 235, 565-567, doi:10.1126/science.235.4788.565.

Lucchitta, B. K. (1990), Young volcanic deposits in the Valles Marineris, Mars?, Icarus, 86, 476-509, doi:10.1016/0019-1035(90)90230-7.

Lucchitta, B. K. (1999), Geologic map of Ophir and Central Candor Chasmata (MTM-05072) of Mars, Geol. Surv. Invest. Ser., I-2568, 
U.S. Geol. Surv., Washington, D. C. [Available at http://pubs.usgs.gov/ imap/i2568/.]

Lucchitta, B. K. (2004), A volcano composed of light-colored layered deposits on the floor of Valles Marineris, Proc. Lunar Planet. Sci. Conf., 35th, Abstract 1881 .

Lucchitta, B. K. (2007), Multiple erosional and depositional episodes in West Candor Chasma, Mars, Proc. Lunar Planet. Sci. Conf, 38th, Abstract 2093

Lucchitta, B. K., and L. M. Bertolini (1989), Interior structures of Valles Marineris, Proc. Lunar Planet. Sci. Conf., 20th, 590-591.

Lucchitta, B. K., A. S. McEwen, G. D. Clow, P. E. Geissler, R. B. Singer, R. A. Schultz, and S. W. Squyres (1992), The canyon system on Mars, in Mars, edited by H. H. Kieffer et al., pp. 453-492, Univ. of Ariz. Press, Tucson.

Lucchitta, B. K., N. K. Isbell, and A. Howington-Kraus (1994), Topography of Valles Marineris: Implications for erosional and structural history, J. Geophys. Res., 99(E2), 3783-3798, doi:10.1029/93JE03095.

Malin, M. C., and K. S. Edgett (2000), Sedimentary rocks of early Mars, Science, 290, 1927-1937, doi:10.1126/science.290.5498.1927.

Malin, M. C., and K. S. Edgett (2001), Mars Global Surveyor Mars Orbiter Camera: Interplanetary cruise through primary mission, J. Geophys. Res., 106(E10), 23,429-23,570, doi:10.1029/2000JE001455.

Malin, M. C., et al. (2007), Context camera investigation on board the Mars Reconnaissance Orbiter, J. Geophys. Res., 112, E05S04, doi:10.1029/ 2006JE002808.

Mangold, N., S. Maurice, W. C. Feldman, F. Costard, and F. Forget (2004), Spatial relationships between patterned ground and ground ice detected by the Neutron Spectrometer on Mars, J. Geophys. Res., 109, E08001, doi:10.1029/2004JE002235.

Masson, P. (1977), Structure pattern analysis of the Noctis LabyrinthusValles Marineris regions of Mars, Icarus, 30, 49-62, doi:10.1016/00191035(77)90120-8.

Masson, P. (1985), Origin and evolution of the Valles Marineris region of Mars, Adv. Space Res., 5(8), 83-92, doi:10.1016/0273-1177(85)90244-3.

McEwen, A. S., et al. (2007), Mars Reconnaissance Orbiter's High Resolution Imaging Science Experiment (HiRISE), J. Geophys. Res., 112, E05S02, doi:10.1029/2005JE002605.

Mège, D., and P. L. Masson (1996), A plume tectonics model for the Tharsis province, Mars, Planet. Space Sci., 44(12), 1499-1546, doi:10.1016/ S0032-0633(96)00113-4.

Morewood, N. C., and G. P. Roberts (1997), The geometry, kinematics and rates of deformation in a normal fault segment boundary, central Greece, Geophys. Res. Lett., 24, 3081-3084, doi:10.1029/97GL03100.

Morewood, N. C., and G. P. Roberts (2000), The geometry, kinematics and rates of deformation within an en echelon normal fault segment boundary, central Italy, J. Struct. Geol., 22, 1027-1047, doi:10.1016/S0191-8141 (00)00030-4.

Morewood, N. C., and G. P. Roberts (2001), Comparison of surface slip and focal mechanism slip data along normal faults: An example from the eastern Gulf of Corinth, Greece, J. Struct. Geol., 23, 473-487, doi:10.1016/ S0191-8141(00)00126-7.

Nedell, S. S., S. W. Squyres, and D. W. Andersen (1987), Origin and evolution of the layered deposits in the Valles Marineris, Mars, Icarus, 70 , 409-441, doi:10.1016/0019-1035(87)90086-8.

Okubo, C. H. (2010), Structural geology of Amazonian-aged layered sedimentary deposits in southwest Candor Chasma, Mars, Icarus, 207, 210-225, doi:10.1016/j.icarus.2009.11.012.

Okubo, C. H. (2012), Spatial distribution of damage around faults in the Joe Lott Tuff Member of the Mount Belknap Volcanics, Utah: A mechanical analog for faulting in pyroclastic deposits on Mars, J. Geophys. Res., 117, E08003, doi:10.1029/2012JE004105.

Okubo, C. H., and A. S. McEwen (2007), Fracture-controlled paleofluid flow in Candor Chasma, Mars, Science, 315(5814), 983-985, doi:10.1126/science.1136855.

Okubo, C. H., K. W. Lewis, A. S. McEwen, and R. L. Kirk (2008), Relative age of interior layered deposits in southwest Candor Chasma based on high-resolution structural mapping, J. Geophys. Res., 113, E12002, doi:10.1029/2008JE003181

Peterson, C. (1981), A secondary origin for the central plateau of Hebes Chasma, Proc. Lunar Planet. Sci. Conf., 12th, 1459-1471.

Peulvast, J. P., and P. L. Masson (1993), Erosion and tectonics in central Valles Marineris (Mars): A new morpho-structural model, Earth Moon Planets, 61, 191-217, doi:10.1007/BF00572245.

Peulvast, J.-P., D. Mège, J. Chiciak, F. Costard, and P. L. Masson (2001) Morphology, evolution and tectonics of Valles Marineris wallslopes
(Mars), Geomorphology, 37, 329-352, doi:10.1016/S0169-555X(00) 00085-4.

Plescia, J. B., and M. P. Golombek (1986), Origin of planetary wrinkle ridges based on the study of terrestrial analogs, Geol. Soc. Am. Bull., 97, 1289-1299, doi:10.1130/0016-7606(1986)97<1289:OOPWRB >2.0. $\mathrm{CO} ; 2$

Rives, T. K. D. Rawnsley, and J. P. Petit (1994), Analogue simulation of natural orthogonal joint set formation in brittle varnish, J. Struct. Geol., 16, 419-429, doi:10.1016/0191-8141(94)90045-0.

Robin, P.-Y. F., and E. C. Jowett (1986), Computerized density contouring and statistical evaluation of orientation data using counting circles and continuous weighting functions, Tectonophysics, 121(2-4), 207-223, doi:10.1016/0040-1951(86)90044-2.

Rossi, A. P., G. Neukum, M. Pondrelli, S. Van Gasselt, T. Zegers, E. Hauber, A. Chicarro, and B. Foing (2008), Large-scale spring deposits on Mars?, J. Geophys. Res., 113, E08016, doi:10.1029/2007JE003062.

Schultz, R. A. (1991), Structural development of Coprates Chasma and western Ophir Planum, central Valles Marineris rift, Mars, J. Geophys. Res., 96, 22,777-22,792, doi:10.1029/91JE02556.

Schultz, R. A. (1998), Multiple-process origin of Valles Marineris basins and troughs, Mars, Planet. Space Sci., 46, 827-834, doi:10.1016/ S0032-0633(98)00030-0.

Schultz, R. A. (2000), Localization of bedding plane slip and backthrust faults above blind thrust faults: Keys to wrinkle ridge structure, J. Geophys. Res., 105, 12,035-12,052, doi:10.1029/1999JE001212.

Schultz, R. A., and A. N. Fori (1996), Fault-length statistics and implications of graben sets at Candor Mensa, Mars, J. Struct. Geol., 18 , 373-383, doi:10.1016/S0191-8141(96)80057-5.

Schultz, R. A., and J. Lin (2001), Three-dimensional normal faulting models of the Valles Marineris, Mars, and geodynamic implications, J. Geophys. Res., 106(B8), 16,549-16,566, doi:10.1029/2001JB000378. Sleep, N. H., and R. J. Phillips (1985), Gravity and lithospheric stress on the terrestrial planets with reference to the Tharsis region of Mars, J. Geophys. Res., 90, 4469-4489, doi:10.1029/JB090iB06p04469.

Sletten, R. S., B. Hallet, and R. C. Fletcher (2003), Resurfacing time of terrestrial surfaces by the formation and maturation of polygonal patterned ground, J. Geophys. Res., 108(E4), 8044, doi:10.1029/2002JE001914.

Smart, K. J., D. Y. Wyrick, and D. A. Ferrill (2011), Discrete element modeling of Martian pit crater formation in response to extensional fracturing and dilational normal faulting, J. Geophys. Res., 116, E04005, doi:10.1029/2010JE003742.

Spencer, J. R. (1983), A tectonic geomorphological classification of the walls of Valles Marineris (Abstract), in Reports of Planetary Geology Program, NASA Tech. Memo. TM-86246, pp. 243-245, NASA, Greenbelt, Md.

Spencer, J. R., and F. P. Fanale (1990), New models for the origin of Valles Marineris closed depressions, J. Geophys. Res., 95, 14,301-14,313, doi:10.1029/JB095iB09p14301

Tanaka, K. L., and M. P. Golombek (1989), Martian tension fractures and the formation of grabens and collapse features at Valles Marineris, Proc. Lunar Planet. Sci. Conf., 19th, 383-396.

Tanaka, K. L., M. P. Golombek, and W. B. Benerdt (1991), Reconciliation of stress and structural histories of the Tharsis region of Mars, J. Geophys. Res., 96, 15,617-15,633, doi:10.1029/91JE01194.

Twiss, R. J., and E. M. Moores (2007), Structural Geology, 532 pp., W. H. Freeman, New York

Watters, T. R. (1991), Origin of Periodically Spaced Wrinkle Ridges on the Tharsis Plateau of Mars, J. Geophys. Res., 96(E1), 15,599-15,616, doi:10.1029/91JE01402.

Watters, T. R. (1993), Compressional tectonism on Mars, J. Geophys. Res., 98(E9), 17,049-17,060, doi:10.1029/93JE01138.

Wilkins, S. J., and R. A. Schultz (2003), Cross faults in extensional settings: Stress triggering, displacement localization, and implications for the origin of blunt troughs at Valles Marineris, Mars, J. Geophys. Res., 108(E6), 5056, doi:10.1029/2002JE001968.

Wilson, L., and J. W. Head III (2002), Tharsis-radial graben systems as the surface manifestation of plume-related dike intrusion complexes: Model and implications, J. Geophys. Res., 107(E8), 5057, doi:10.1029/ 2001JE001593.

Witbeck, N. E., K. L. Tanaka, and D. H. Scott (1991), Geologic map of the Valles Marineris region, Mars, U.S. Geol. Surv. Misc. Invest. Map, I-2010.

Wyrick, D., D. A. Ferrill, A. P. Morris, S. L. Colton, and D. W. Sims (2004), Distribution, morphology, and origins of Martian pit crater chains, J. Geophys. Res., 109, E06005, doi:10.1029/2004JE002240. 